\title{
THE DYNAMICS OF OCEAN HEAT TRANSPORT VARIABILITY
}

\author{
Steven R. Jayne ${ }^{1,2}$ \\ MIT-WHOI Joint Program in Oceanography \\ Woods Hole Oceanographic Institution \\ Woods Hole, Massachusetts, USA
}

\author{
Jochem Marotzke \\ School of Ocean and Earth Science \\ Southampton Oceanography Centre \\ Southampton, England, UK
}

\begin{abstract}
The north-south heat transport is the prime manifestation of the ocean's role in global climate, but understanding of its variability has been fragmentary owing to uncertainties in observational analyses, limitations in models, and the lack of a convincing mechanism. We review the dynamics of global ocean heat transport variability, with an emphasis on timescales from monthly to interannual. We synthesize relatively simple dynamical ideas and show that together they explain heat transport variability in a state-of-the-art, high-resolution ocean general circulation model. Globally, the crossequatorial seasonal heat transport fluctuations are close to $\pm 3 \times 10^{15} \mathrm{~W}$, the same amplitude as the crossequatorial seasonal atmospheric energy transport. The variability is concentrated within $20^{\circ}$ of the equator and dominated by the annual cycle. The majority of the variability is due to wind-induced current fluctuations in which the time-varying wind drives Ekman layer mass
\end{abstract}

transports that are compensated by depth-independent return flows. The temperature difference between the mass transports gives rise to the time-dependent heat transport. It is found that in the heat budget the divergence of the time-varying heat transport is largely balanced by changes in heat storage. Despite the Ekman transport's strong impact on the time-dependent heat transport, the largely depth-independent character of its associated meridional overturning stream function means that it does not affect estimates of the time-mean heat transport made by one-time hydrographic surveys. Away from the tropics the heat transport variability associated with the depth-independent gyre and depthdependent circulations is much weaker than the Ekman variability. The non-Ekman contributions can amount to a $0.2-0.4 \times 10^{15} \mathrm{~W}$ standard deviation in the heat transport estimated from a one-time hydrographic survey.

\section{INTRODUCTION}

\subsection{Motivation}

The turbulent circulations of the ocean and atmosphere influence climate in a complicated exchange of heat, mass, and momentum. The complexity of this system coupled with its sparse observational coverage has made interpretation and understanding of several crucial processes difficult. Further, its intricacies limit our ability to predict anthropogenic impacts on climate. This paper addresses the ocean's role in climate by investigating temporal variability in ocean heat transport, with an emphasis on global ocean dynamics.

Estimates of the time-mean ocean heat transport show that the ocean carries the same order of magnitude of energy away from the tropics toward the poles as the atmosphere [Vonder Haar and Oort, 1973; Hastenrath,

\footnotetext{
${ }^{1}$ Now at Cooperative Institute for Research in Environmental Sciences and Department of Physics, University of Colorado, Boulder, Colorado, USA.

${ }^{2}$ Also at National Center for Atmospheric Research, Boulder, Colorado, USA.
}

1982; Carissimo et al., 1985; Peixoto and Oort, 1992; Trenberth and Solomon, 1994; Keith, 1995; Trenberth et al., 2001]. Keith [1995] concluded that the time-mean ocean heat transport calculated as the residual to close the atmospheric energy budget has achieved the same accuracy as direct hydrographic methods. Though the uncertainties in the transports may be as large as $0.7 \mathrm{PW}$ $\left(1 \mathrm{PW}=10^{15} \mathrm{~W}\right)$ and errors still remain in the partition between the ocean and the atmosphere, the estimates are believed to be good enough to constrain coupled ocean-atmosphere climate models. Macdonald and Wunsch [1996] made a dynamically and kinematically consistent estimate of the global oceanic transports of mass, heat, and freshwater based on an inverse model of a collection of one-time hydrographic sections. With the completion of the World Ocean Circulation Experiment (WOCE), more hydrographic sections are now available and a better estimate will be possible [e.g., Ganachaud, 1999; Ganachaud and Wunsch, 2000]. While uncertainties still exist, the sign of the time-mean ocean heat transport is known over the global ocean, and quantifiable error estimates can be made.

Since the time mean of heat transport has been rea- 
sonably addressed, it is timely to consider its time dependence. Neither its nature nor its magnitude is well known, with conflicting estimates differing not only in magnitude, but also in sign. Therefore it represents a large gap in our understanding of the ocean's dynamics. Furthermore, the energetic variability in the ocean due to mesoscale eddies, wave motions, or atmospherically driven transients may or may not impact our ability to observe the time-mean transport. One of the uses for hydrographic surveys, either single lines or large international programs such as WOCE, is that the annualmean ocean heat transport at a latitude is estimated from a one-time ocean section. These estimates of heat transport rely on the method used by Hall and Bryden [1982] or on inversions of hydrographic data [e.g., Roemmich and Wunsch, 1985; Macdonald and Wunsch, 1996]. However, if there is strong ocean variability, the estimate of the heat transport may be badly corrupted. Hall and Bryden [1982] assessed the potential error introduced by eddy noise on their estimate of the heat transport at $24^{\circ} \mathrm{N}$ and found that it could be as large as $25 \%$ of the total and was the largest error in their estimate. Additionally, seasonal biases may corrupt estimates of heat transport owing to the predominance of summertime oceanographic field work, particularly at high latitudes. Therefore it is important that the ocean heat transport variability be quantified and its impact on hydrographic heat transport estimates be evaluated.

\subsection{Background}

Throughout this paper we will define as the northward "heat transport" the integral of the product $\rho c_{p} \theta v$ over the area of a zonal ocean section, where $\rho$ is the in situ density, $c_{p}$ is the specific heat per unit mass of water at constant pressure, $\theta$ is the potential temperature, and $v$ is the northward velocity. Warren [1999] points out that this is an approximation to the internal energy transport, or more accurately the transport of enthalpy plus potential energy, and would be more appropriately referred to as such. However, by convention the vernacular terminology of "heat transport" shall be used.

The concept of "Ekman" heat transport and the physics underlying it is the key to understanding a large part of the time-varying ocean heat transport. It was used for estimating heat transport from observations by Bryan [1962] and Kraus and Levitus [1986] and then later by Levitus [1987], Adamec et al. [1993], and Ghirardelli et al. [1995]. Kraus and Levitus [1986] give the definition of the Ekman heat transport as the following integral across a coast-to-coast zonal section:

$$
Q_{E}(t)=-\int \rho_{0} c_{p} \frac{\tau_{x}}{f \rho_{0}}\left(T_{\mathrm{Ek}}-\langle[\theta]\rangle\right) d x,
$$

where $f$ is the Coriolis parameter, $\boldsymbol{\rho}_{0}$ is the reference density, $T_{\mathrm{Ek}}(x)$ is the temperature of the surface Ekman layer, $\langle[\theta]\rangle$ is the section-averaged potential temperature, and $\tau_{x}(x)$ is the zonal wind stress. This equation expresses the heat transport as the integral of the meridional Ekman-layer mass flux, $-\tau_{x} /\left(f \rho_{0}\right)$, which is at right angles to the wind, times the difference between the Ekman layer temperature and the section-averaged potential temperature. It implies that for any given section the mass transport in the Ekman layer is compensated by a return flow distributed uniformly across the depth and zonal extent of the section.

The question arises whether (1) is merely a definition to facilitate convenient bookkeeping, with no relation to any real phenomenon necessarily implied. On the other hand, it could be that under some circumstances, (1) appropriately describes a physical process and merely needs to be placed in a proper theoretical framework. We will show that the latter is true. The critical quantity is the (assumed or real) temperature profile of the flow returning the Ekman mass transport. In particular, the studies cited above assumed that the time-mean and the time-dependent Ekman return flows have the same depth structure, which we will show to be incorrect.

There are other difficulties in interpreting the role of the Ekman heat transport in climate processes. First, the Ekman heat transport is only one component of the total transport; changes in it may be unaffected, reinforced, or completely offset by changes in other parts of the system. Second, the concept of Ekman transport is not applicable within a few degrees of the equator, as the Coriolis parameter vanishes there. Third, none of the observational investigations can take into account the finding of Bryan [1982] that the meridional wind plays an increasingly important role as one approaches the equator.

The assumption that the return flow for the timevarying Ekman transport is "barotropic" (independent of depth) finds some support from theory of time-dependent ocean circulation [Veronis and Stommel, 1956; Willebrand et al., 1980] and modeling studies [Bryan, 1982; Böning and Herrmann, 1994], but a comprehensive dynamical argument is still outstanding. Furthermore, there is neither a theoretical, nor an observational, nor a modeling basis to assume that the time-mean Ekman transport should be returned barotropically. In fact, Anderson et al. [1979] and Willebrand et al. [1980] clearly indicate that a time-mean forcing drives a circulation that is strongly influenced by stratification and nonlinear effects and generally is not barotropic. More recently, Klinger and Marotzke [2000] have argued that the timemean Ekman layer mass transport is returned at relatively shallow depths. Given a typical ocean temperature distribution, a shallower return flow translates into a warmer return flow and decreases the strength of the heat transport compared with a barotropic return flow. Therefore, while the time-dependent portions of the Ekman heat transports, defined by (1), may well be reliable estimates, the time-mean component should be viewed with suspicion.

While some of the dynamics underlying the role of the fluctuating wind stress in forcing ocean heat transport variability have been discussed in previous studies, 
they have never been put together in a cohesive argument. The first studies to examine the issue were those by Bryan and Lewis [1979] and Bryan [1982], who used a global ocean general circulation model forced with observed wind fields. In his seminal discussion, Bryan [1982] argued that changes in the zonally integrated wind stress lead directly to changes in the Ekman mass transport, which cause a compensating barotropic flow. The resulting meridional overturning circulation leads to a time-dependent heat transport, as water in the Ekman layer is warmer than that of the compensating flow. However, there was only a weak theoretical underpinning for these arguments. Furthermore, the time-mean response is combined with the time-varying response in the analysis, making interpretation difficult and obscuring the fact that the dominant physics that determines the mean flow is different from that which determines the time-varying flow.

Aspects of the ocean response to variable forcing were explained by Willebrand et al. [1980]. They provided a theoretical basis for the response of the ocean to forcing on large spatial scales at timescales longer than a day. However, their work did not directly address ocean heat transport. They used a one-layer shallow water model and arguments based on quasi-geostrophy that explicitly exclude the dynamics that will be shown to be responsible for the seasonally varying ocean heat transport. Willebrand et al. [1980] showed that the fluctuating part of the wind stress drives ocean variability that is governed by linear, barotropic dynamics in latitudes away from the equator [see also Gill and Niiler, 1973; Philander, 1978]. Furthermore, despite claims to the contrary [Bryden et al., 1991], there is observational evidence of deep ocean currents forced directly by timevarying wind stress fields [Koblinsky and Niiler, 1982; Niiler and Koblinsky, 1985; Brink, 1989; Koblinsky et al., 1989; Luther et al., 1990; Samelson, 1990; Chave et al., 1992; Niiler et al., 1993]. There is also observational evidence of large-scale wind forcing of sea surface height fluctuations [Fu and Davidson, 1995; Chao and Fu, 1995; Fu and Smith, 1996; Fukumori et al., 1998; Stammer et al., 2000; Tierney et al., 2000].

The work of Willebrand et al. [1980] is only applicable to the middle- and high-latitude oceans. A connection to the low latitudes and in particular the equator must be made. Some progress on this problem was made by Schopf [1980], who used an idealized model of the ocean to discuss the role of variable wind forcing in the tropical ocean heat transport. He found that heat transport variability near the equator could be described by a simple linear Ekman transport model. Directly on the equator, where the definition of Ekman transport becomes meaningless since the Coriolis parameter is zero, he argued that by continuity, the pressure force directly drives the seasonally varying flow across the equator. However, Schopf's [1980] work was done on a one-hemisphere model, and his boundary conditions required that the flow be symmetric about the equator. Therefore it is warranted to examine whether his findings apply to a global model.

This paper evaluates the theoretical arguments for using an equation of form (1) and determines when, where, and how it is appropriate to use it to describe the ocean. In many respects the trio of studies by Willebrand et al. [1980], Schopf [1980], and Bryan [1982] provides the pieces for a dynamical picture of the driving of the seasonal ocean heat transport by the seasonally varying wind. However, these arguments have never been gathered together in a cohesive theory and have not generally been embraced by the current literature. For example, Garternicht and Schott [1997] correlated heat transport and wind stress fluctuations, but they did not provide a detailed dynamical explanation. Most recently, Kobayashi and Imasato [1998] diagnosed the seasonal variability of the heat transport using the observed wind stress and hydrographic data. Again, however, no dynamical justification for the calculation is given. Finally, the global nature of the heat transport variability has not been visited since the work of Bryan [1982], as more recent investigations have explored individual basins: Böning and Herrmann [1994] and Yu and MalanotteRizzoli [1998] in the Atlantic Ocean, and McCreary et al. [1993], Wacongne and Pacanowski [1996], Garternicht and Schott [1997], and Lee and Marotzke [1998] in the Indian Ocean.

\subsection{Structure}

This paper connects the observations and modeling work of the seasonal cycle of heat transport to a more dynamical description. First, the previous estimates of the seasonal cycle of heat transport are summarized (section 2). Second, a state-of-the-art ocean general circulation model (OGCM) is used to understand the response of the ocean's meridional overturning to the seasonally varying wind stress (section 3 ). Next, the fluctuations in the circulation owing to the wind stress variability are related to the ocean heat transport (section 4). Section 5 presents a comparison of the model's heat transport variability with prior estimates from observations and models, an examination of the seasonal heat balance to understand the impact of the timevarying heat transport on the local heat budget, and a discussion of the implications of heat transport variability on observing the time-mean heat transport. Conclusions follow in section 6 .

\section{SUMMARY OF PREVIOUS METHODS}

The seasonal cycle of ocean heat transport has been the subject of several avenues of investigation. Direct observation of the time-dependent heat transport by the ocean on any reasonable timescale is prohibited by the impossibility of sampling the full ocean depth over the vast range of spatial scales required. There have been a handful of studies that have addressed the variability of 
the heat transport across single zonal sections, notably, the work of Molinari et al. [1990] and Baringer and Molinari [1999] at $26.5^{\circ} \mathrm{N}$ and Sato and Rossby [2000] at $36^{\circ} \mathrm{N}$ in the Atlantic, and the model-based analysis by Wilkin et al. [1995] at $24^{\circ} \mathrm{N}$ in the Pacific. Though hydrographic surveys do provide some measure of the eddy variability along their sections, they are strongly aliased in time. Therefore estimates of the global variability have had to rely on indirect approaches. These have been based on models [Bryan and Lewis, 1979; Bryan, 1982] or observed changes in oceanic heat storage, combined either with atmospheric and satellite observations [Oort and Vonder Haar, 1976; Carissimo et al., 1985], surface flux observations [Hsiung et al., 1989], or wind stress and surface temperatures to estimate changes in the Ekman component of the heat transport [Kraus and Levitus, 1986; Levitus, 1987; Adamec et al., 1993; Ghirardelli et al., 1995].

\subsection{Atmospheric Estimates}

Oort and Vonder Haar [1976] used a combination of satellite radiation, atmospheric radiosonde, and oceanic heat storage data to calculate the ocean heat transport in the Northern Hemisphere as the residual necessary to close the energy balance at the top of the atmosphere. They inferred large seasonal variations particularly in the tropics where the oceans transport large amounts of heat across the equator from the summer hemisphere to the winter hemisphere. Carissimo et al. [1985] updated the study of Oort and Vonder Haar [1976] using data covering the entire globe. They too found a large seasonal variation in the ocean's inferred heat transport. Peak to peak, their annual cycle of ocean heat transport across the equator was $7.3 \pm 3 \mathrm{PW}$. Over the midlatitudes the amplitude was smaller, but still directed northward during boreal winter (austral summer) and southward during boreal summer (austral winter). The large error bars on this estimate are due largely to the poor quality and general lack of ocean heat storage data available at the time of their study.

\subsection{Ekman Heat Transport}

Kraus and Levitus [1986] calculated the annual heat transport variations across the Tropics of Cancer and Capricorn by the Ekman heat transport using (1) and found that the amplitude of the annual cycle was the same order of magnitude as the annual-mean Ekman heat transport in both the Pacific and Atlantic Oceans. This work was extended by Levitus [1987], who calculated the Ekman heat transport for all three ocean basins over their latitudinal extents using climatological data sets for temperature [Levitus, 1982] and wind stress [Hellerman and Rosenstein, 1983]. The essential premise of these calculations is that the atmospheric wind stress drives an Ekman transport in the surface layer which is accompanied by a compensating return flow which is distributed evenly over the zonal section. More recently, Adamec et al. [1993] used wind stress values and tem- peratures computed from the Comprehensive OceanAtmosphere Data Set (COADS) to compute the Ekman heat transport. Ghirardelli et al. [1995] used satellitederived wind stress from the Special Sensor Microwave Imager (SSM/I) and sea surface temperature from the advanced very high resolution radiometer (AVHRR). All these studies qualitatively give the same picture of the annual cycle of the Ekman heat transport. Over the world ocean the annual cycle is of the order of $8 \mathrm{PW}$ peak to peak in the tropics. It is strongest in the Pacific and Indian Oceans and noticeably weaker in the Atlantic Ocean. Additionally, the phase of the annual cycle reverses in the midlatitudes at around $20^{\circ}$.

\subsection{Ocean General Circulation Models}

Global ocean general circulation models were used by Bryan and Lewis [1979], Bryan [1982], and Meehl et al. [1982] to explore heat transport variability. Bryan and Lewis [1979] found a significant seasonally varying heat transport. Meehl et al. [1982] added a seasonally varying, surface heat flux forcing to a similar ocean model and used a wind stress field that had both a semiannual harmonic and an annual harmonic. Their results were similar to those of Bryan and Lewis [1979] for the seasonally varying heat transport, with the addition of a semiannual signal in the heat transport due to the different forcing fields. Lau [1978] also found a large annual cycle in the ocean heat transport but did not directly attribute it to the seasonal wind stress cycle. Bryan [1982] found that while the zonal wind stress seasonal cycle forced an ocean heat transport from the summer hemisphere to the winter hemisphere, the seasonal cycle in the meridional wind acted to suppress the heat transport seasonal cycle in the tropics. This effect was strongest close to the equator, where a meridional surface layer transport can be driven directly by the meridional wind, owing to the Coriolis parameter going to zero there.

More recently, models of various resolutions have been applied to basin-scale studies. Böning and Herrmann [1994] and Yu and Malanotte-Rizzoli [1998] have examined the Atlantic Ocean, while McCreary et al. [1993], Wacongne and Pacanowski [1996], Gartemicht and Schott [1997], and Lee and Marotzke [1998] looked at the Indian Ocean. These authors all found strong annual cycles in the ocean heat transport and confirmed the importance of the wind on the ocean heat transport variability. However, the Pacific Ocean has not been investigated, and there have been no recent model studies of the global, time-dependent ocean heat transport since Bryan [1982] and Meehl et al. [1982]. Further, all the above works use monthly wind stress fields, and it is unknown whether higher-frequency wind stress fields will introduce high-frequency ocean heat transport oscillations. 


\subsection{In Situ Data}

The most recent global estimate of the time mean and seasonal cycle of ocean heat transport was made by Hsiung et al. [1989] using ocean heat storage data calculated from the Master Oceanographic Observations Data Set (MOODS). They closed their energy budget at the ocean surface with fluxes computed using the bulk formulae. The ocean heat transport was calculated as the residual needed to close the energy budget in the ocean after accounting for surface fluxes and storage terms. This work expanded that of Lamb and Bunker [1982] in the Atlantic to cover the Pacific and Indian Oceans as well. Their estimate of the annual cycle of heat transport across the equator by the ocean had a peak-to-peak amplitude of $4.4 \pm 1.4 \mathrm{PW}$. Overall, the picture of the annual cycle they presented was consistent with that of Bryan [1982], with the annual cycle reversing sign in midlatitudes, as was also seen in the studies of Ekman heat transport discussed above. However, they found the annual cycle lagged several months behind that of Carissimo et al. [1985].

The consensus of the previous studies is that there is a large seasonal cycle driven by the seasonal cycle of wind stress. However, there is disagreement about both its magnitude and dynamics. The global studies by Hsiung et al. [1989], Bryan [1982], and Levitus [1987] give a generally consistent picture of the seasonal heat cycle, though differing in details. In contrast, the study of Carissimo et al. [1985] stands out as significantly different from the other estimates, most likely because their data did not properly resolve the seasonal cycle in ocean heat storage.

\section{VARIABILITY IN OCEAN MERIDIONAL OVERTURNING}

In this section we examine the dynamics of the seasonal changes in the ocean circulation and relate it to the time-varying wind stress. In the next section (section 4) it will be shown how the seasonal changes in circulation affect the ocean heat transport. To elucidate the dynamics responsible for the variability, we present a description of the global characteristics of the high-frequency, time-varying ocean heat transport from a state of the art OGCM (the Parallel Ocean Climate Model (POCM)) [Semtner and Chervin, 1988, 1992; Stammer et al., 1996; McClean et al., 1997]. The numerical simulation output from run 4_B of the POCM is used to calculate ocean mass and heat transport at 3-day intervals. The POCM is a primitive-equation, level model configured for the global ocean between $75^{\circ} \mathrm{S}$ and $65^{\circ} \mathrm{N}$, with realistic topography, and has an average grid spacing of $1 / 4^{\circ}$. The model was forced with 3-day averages of the $10-\mathrm{m}$ wind stress fields from the European Centre for MediumRange Weather Forecasts (ECMWF) for the period between 1987 and 1996. The monthly surface heat fluxes were derived from ECMWF analyses by Barnier et al.
[1995]. The surface layer temperatures and salinities were restored to the Levitus et al. [1994] and Levitus and Boyer [1994] climatology on a monthly timescale using the Haney [1971] scheme. The fidelity of this particular model simulation was discussed in detail by Stammer et al. [1996], who found the model successfully simulates the seasonal cycle, though the overall amplitude of the seasonal heat storage was weaker than observed in altimeter observations from TOPEX/Poseidon. This weakness is largely attributable to the model's lack of an explicit mixed-layer parameterization [e.g., Large et al., 1994]. However, there is reason to believe that the model is providing a reasonable simulation of the seasonal variations in mass and heat transport. Böning et al. [2001] found that three OGCMs that used different vertical coordinate systems (geopotential, isopycnic, and sigma coordinates) all were in close agreement in the major aspects of their seasonal cycles. Their findings suggest that the dynamics of the seasonal heat transport variability are robust to model formulation.

\subsection{The Seasonal Cycle in Meridional Overturning}

The motivation for this discussion comes from examining the volume transports across oceanic sections. We define Ekman transport as the sum of the shear velocities in the upper $100 \mathrm{~m}$ of the model (top four model layers) relative to the velocity at $117.5 \mathrm{~m}$ (the fifth model layer) below which the wind stress shear did not appear to penetrate. The barotropic transport is then taken as the vertical integral of the velocity over the full ocean depth after the Ekman velocity has been removed. In the POCM, as in most other models, there is a near-perfect compensation between the deviations from the timemean Ekman transport across a section and the deviations from the time-mean barotropic transport. Figure 1 shows the balance between the two at $30^{\circ} \mathrm{N}$ in the Pacific Ocean. The correlation coefficient between the timevarying Ekman transport and the time-varying barotropic transport is -0.99 .

What dynamics create this compensation? In a model that has the rigid-lid approximation imposed, this compensation must be perfect. That is, there can be no net transport across a closed oceanic section, and therefore the barotropic transport must equal the Ekman transport. In a numerical model with a free surface, as in the true ocean, it is less clear that the time-varying Ekman transport must equal the barotropic transport, as accumulations of mass through closed oceanic sections can lead to free-surface displacements. Why the compensation persists is a key question in explaining the role of the time-varying wind forcing the heat transport fluctuations; we will address it in section 3.4.

The meridional overturning stream function, defined as the vertical cumulative integral of zonally integrated meridional flow, is a standard way to examine the structure of the flow. The time-mean meridional overturning stream function from the POCM is shown in Figure 2; for the individual basins it is not defined south of $37^{\circ} \mathrm{S}$ 


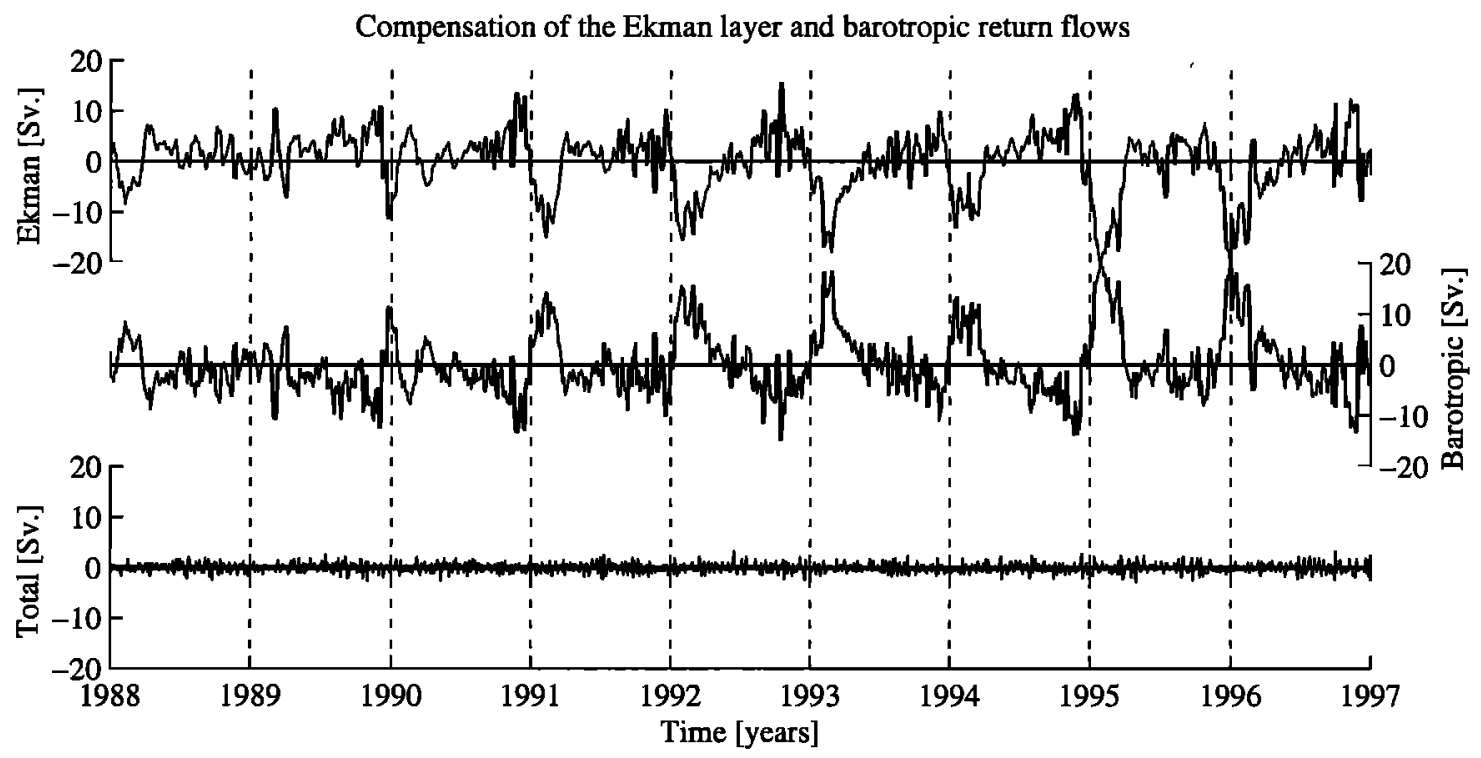

Figure 1. Deviations from the time-mean Ekman transport compared with deviations from the time-mean barotropic transport at $30^{\circ}$ in the Pacific Ocean, showing a high degree of compensation. The sum of the two is shown in the bottom panel.

(the Cape of Good Hope). While this paper almost exclusively concerns time-varying circulation and transports, we feel compelled to show the time-mean meridional overturning for reference. The POCM represents most of the familiar gross features of the overturning circulation: the Atlantic deep cell associated with northern deep water formation, the relatively symmetric thermocline circulation and the inflows of bottom water into the deep Pacific, and the thermocline circulation in the South Indian Ocean. Notice the weakness of northward flow of deep water from the Southern Ocean into the Atlantic and Indian Oceans [Macdonald and Wunsch, 1996; Ganachaud et al., 2000].

The seasonal cycle of the overturning stream function can be represented by the mean conditions in January minus the mean conditions in July, averaged over the last 9 years of the model run (1988-1997). Figure 3 shows that the seasonal patterns differ radically from the time-mean overturning circulation. In the time mean, the return flow to balance the surface Ekman transport is highly baroclinic (depth varying) with reversals of the flow at depth. The seasonally varying component, on the other hand, is largely depth independent, with the return flow for the surface currents showing no deep reversals. The Pacific Ocean displays the strongest difference, with the time-mean overturning being essentially antisymmetric about the equator and the seasonally varying overturning being nearly symmetric about the equator.

Structural differences between the time-mean and seasonal overturning circulations have been noted before [Bryan, 1982; England et al., 1994; Nakano et al., 1999]; however, they have never been satisfactorily given a dynamical explanation. Rarely are they even presented separately; rather, they are usually presented as January conditions and July conditions, which obfuscates the differences between the time-mean and time-varying components [e.g., Bryan, 1982; Böning and Herrmann, 1994; Wacongne and Pacanowski, 1996; Garternicht and Schott, 1997] (see Lee and Marotzke [1998] and Nakano et al. [1999] for exceptions). The amplitude of the seasonal cycle of the overturning circulation in the equatorial region is about 50 sverdrups (Sv) for the world total, which is comprised of $20 \mathrm{~Sv}$ in the Indian Ocean, $25 \mathrm{~Sv}$ in the Pacific Ocean, and 5 Sv in the Atlantic Ocean. The actual velocities associated with these seasonal overturning circulations are quite small; the deep horizontal velocities are of the order of $10^{-3} \mathrm{~m} \mathrm{~s}^{-1}$, and the vertical velocities are of the order of $10^{-6} \mathrm{~m} \mathrm{~s}^{-1}$, leading to seasonal displacements of $20 \mathrm{~km}$ in the horizontal and $20 \mathrm{~m}$ in depth. The Ekman layer horizontal velocities are obviously much larger, of the order of $0.1 \mathrm{~m} \mathrm{~s}^{-1}$.

\subsection{Dynamical Meridional Overturning}

To examine the behavior of the POCM, the velocity fields were used to compute meridional overturning stream functions. Following Lee and Marotzke [1998], the meridional velocity fields from the POCM were broken into three separate dynamical contributions according to

$$
\begin{aligned}
v(x, y, z)= & \frac{1}{H} \int_{-H}^{0} v(x, y, z) d z \\
& +\left[v_{e}(x, y, z)-\frac{1}{H} \int_{-H}^{0} v_{e}(x, y, z) d z\right] \\
& +v_{s h}(x, y, z)
\end{aligned}
$$



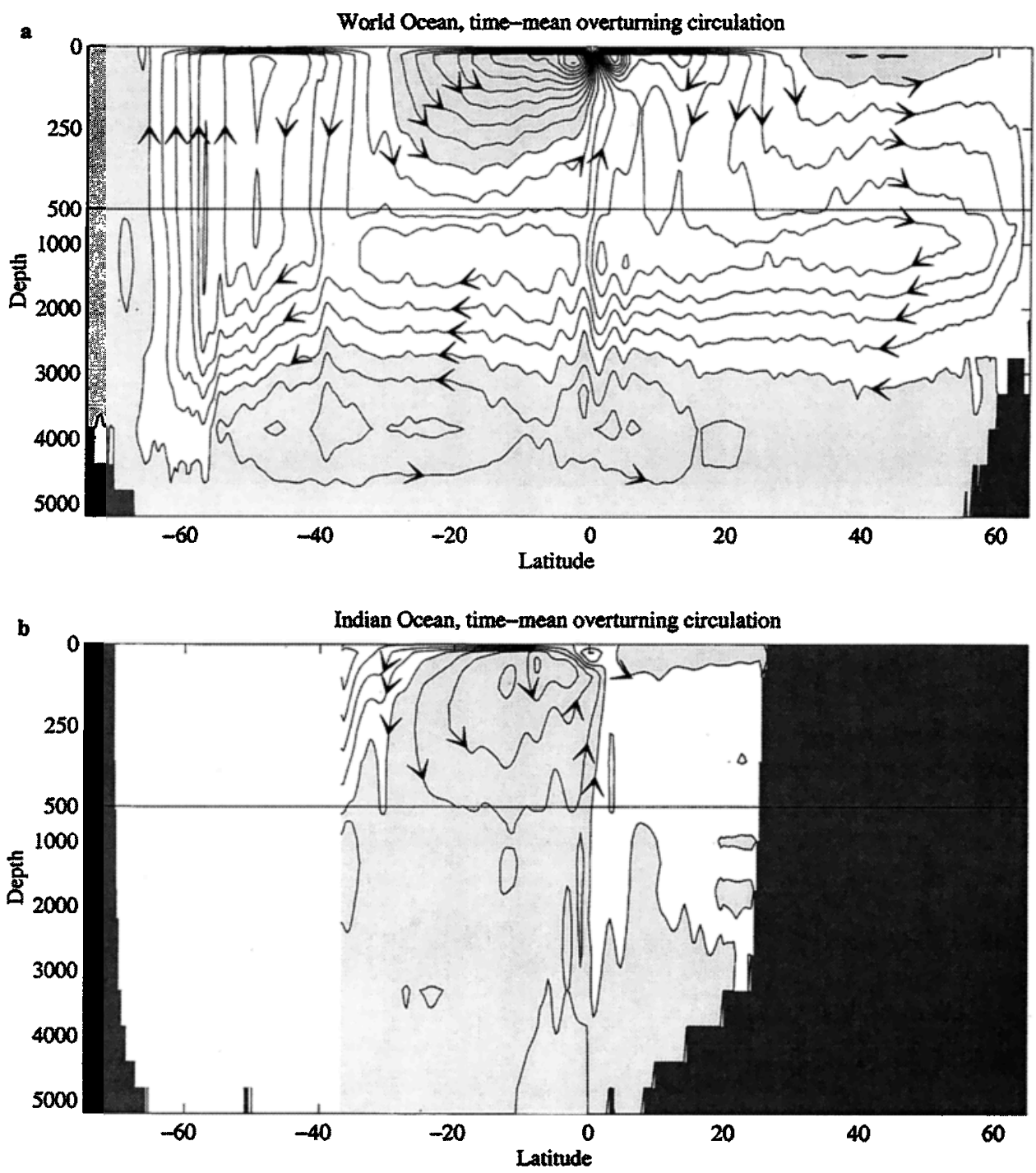

Figure 2. Time-mean overturning circulation for (a) the world ocean and (b) the Indian Ocean, (c) the Pacific Ocean, and (d) the Atlantic Ocean. Negative values of the stream function are shaded and indicate counterclockwise overturning. Contour interval for the world ocean is 5 sverdrups (Sv), and the interval for the individual basins is $2.5 \mathrm{~Sv}$.

where $H=H(x, y)$ is the ocean depth. The three components are in the order they appear in equation (2): The first component is the contribution to the meridional velocity due to the external mode (or barotropic gyre circulation) flowing over varying topography. Essentially, it is the flow that is governed by the Sverdrup relation taking into account time dependence, bottom topography, and frictional effects. The second component is the surface Ekman flow $\left(v_{e}\right)$ minus its vertical average to represent its barotropic compensation. The Ekman component of velocity, $v_{e}$, is taken here to be the shear velocity in the four surface levels referenced to velocity at the fifth model level $(117.5 \mathrm{~m})$; however, nearly all the Ekman transport takes place in the top level (uppermost $25 \mathrm{~m}$ ). Note that the vertical integral of this term is zero, and hence the barotropic velocities associated with it are not part of the first term. (3) The third component is the vertical shear flow $\left(v_{s h}\right)$, which is generally associated with thermal wind shear balanced by zonal density gradients, as well as smaller contributions from the ageostrophic shear from frictional and nonlinear effects.

A simple estimate of the meridional velocities arising solely from wind stress driving the Ekman layer with an associated depth-averaged compensating flow was estimated from

$$
v_{W}(x, y, z)=\frac{\delta_{1, k}}{h} \frac{\tau_{\lambda}(x, y)}{f \rho_{0}}+\frac{1}{H} \frac{\tau_{\lambda}(x, y)}{f \rho_{0}},
$$

where $h$ is the thickness of the POCM surface model layer $(25 \mathrm{~m})$ and $\delta_{i, j}$ is the Kronecker delta. This estimate of the velocity field is used to compute a seasonal overturning circulation that is described by just the Ek- 

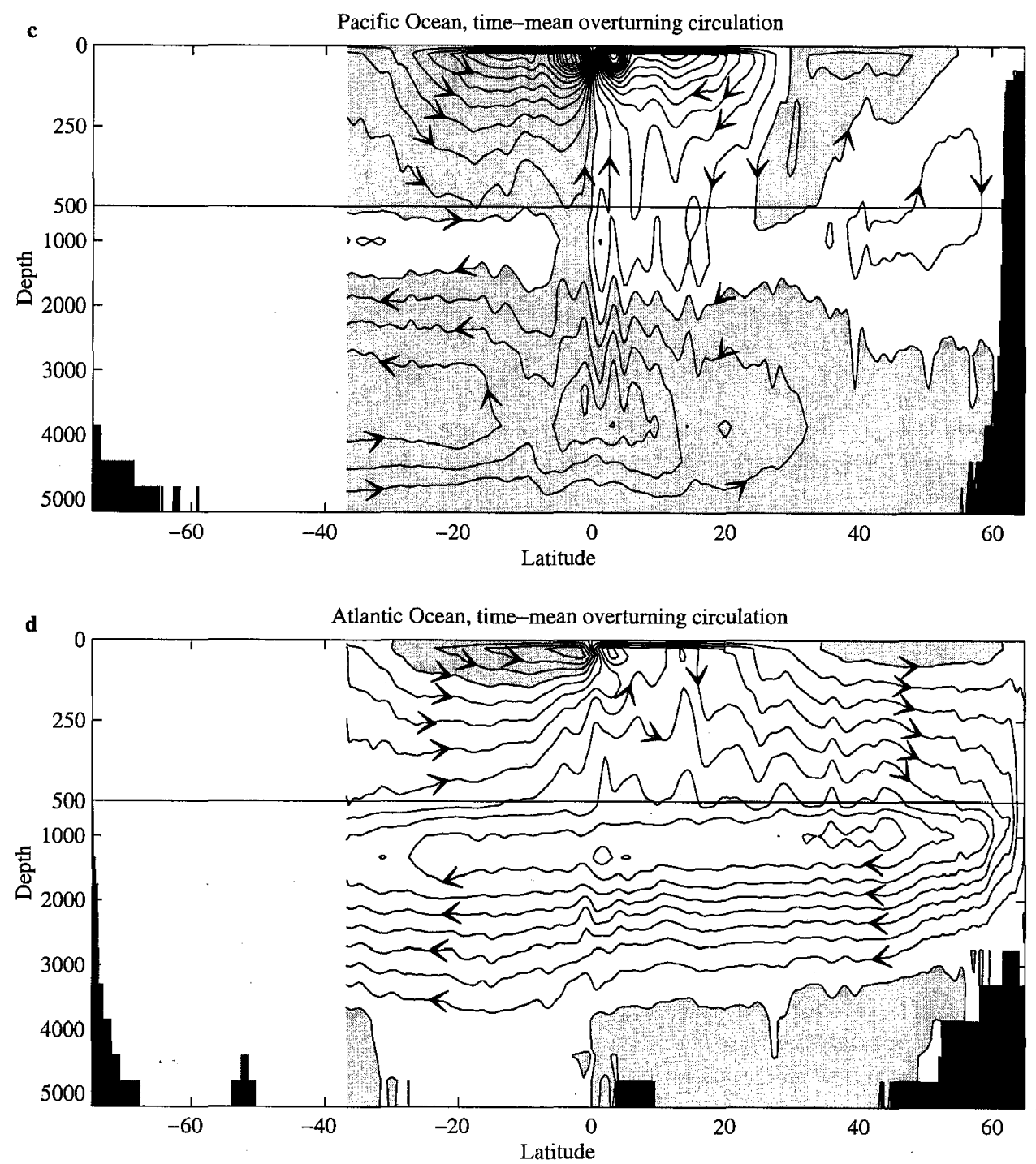

Figure 2. (continued)

man layer and its barotropic return flow. This overturning circulation is then comparable to those derived from the POCM to test if this simple set of dynamics can explain the structure of the overturning circulations.

The seasonal overturning circulations are shown in Figure 4. The result from the simple Ekman approximation (derived from equation (3) and shown in Figure 4b) corresponds well in both magnitude and spatial structure to that from the full numerical model (Figure 3a) and the Ekman component of dynamical meridional overturning (the second term of equation (2) and shown in Figure 4a). The exception is at the equator, where the simple Ekman model does not represent the shear between the surface layers permitted by the vanishing Coriolis parameter and stratification there. On the equator, in the simplified Ekman model, there appears a narrow counterrotating cell over the full ocean depth instead of being confined to the upper $25 \mathrm{~m}$ as in the full POCM. Overall, the similarity between the two results suggests that the simple Ekman model contains the dominant physical processes. The equatorial surface cir- culation is directly driven by the seasonal cycle of the meridional wind. Therefore the counter flow also does not appear in the circulation derived from the Ekman approximation using only the zonal wind stress and (3).

\subsection{The Seasonal Wind Field}

Before the model simulations and dynamics are discussed further, the general nature of the time-varying wind should be examined. The characteristics of the variable wind stress field have been discussed before [Hellerman, 1967; Vinnichenko, 1970; Willebrand, 1978; Hellerman and Rosenstein, 1983], with one crucial exception. Figure 5 shows the seasonal wind stress field (from ECMWF) and the zonal integral of its zonal component. Notable features in the annual cycle of wind stress arise from the strengthening of the Aleutian and Icelandic lows in boreal winter, the austral winter strengthening of the circumpolar winds in the Southern Hemisphere, as well as the strong monsoonal cycle in the western Indian Ocean [Peixoto and Oort, 1992]. Perhaps the most surprising feature is that the integral of the zonal wind 

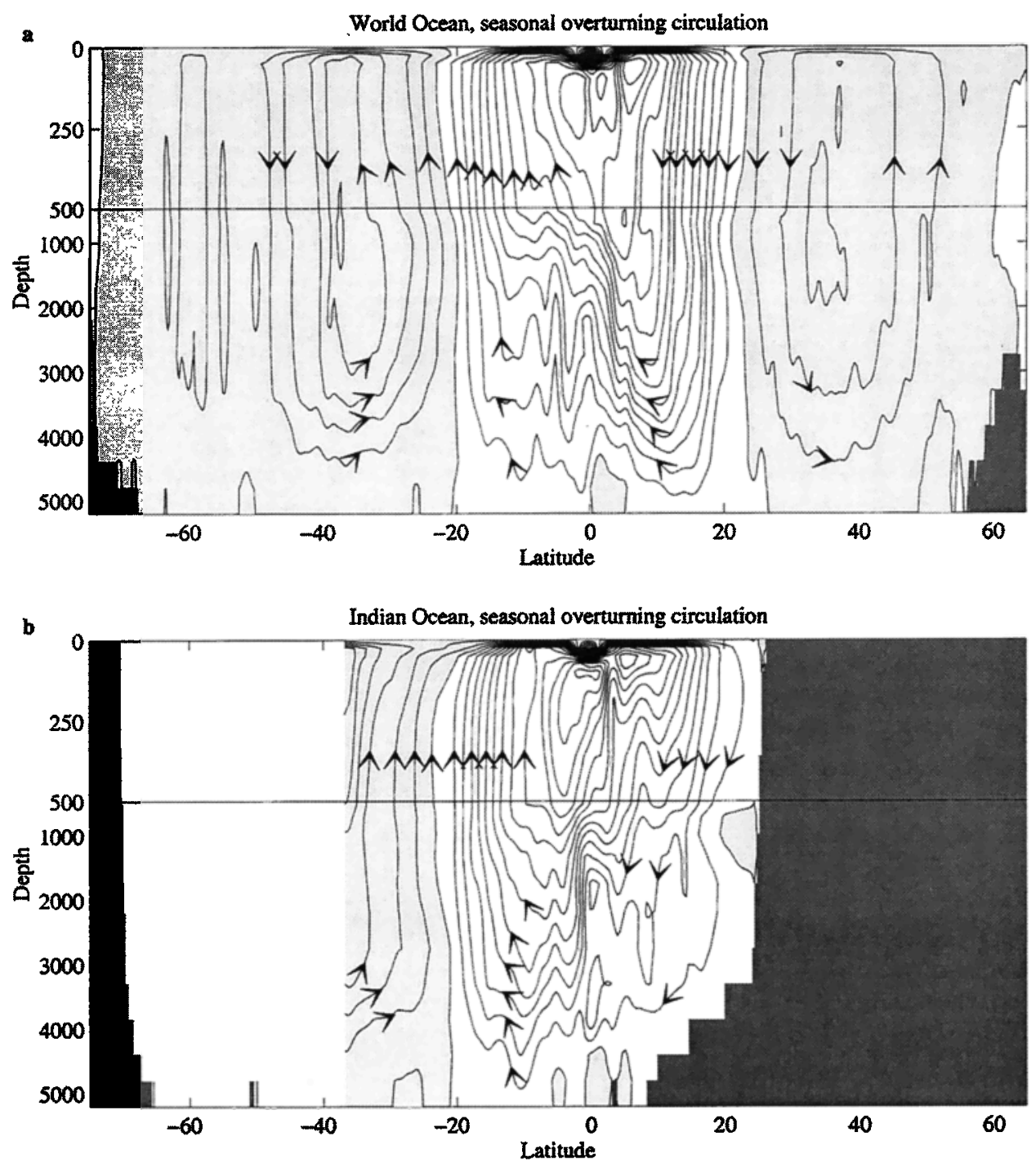

Figure 3. Seasonal (January minus July) overturning circulation for (a) the world ocean and (b) the Indian Ocean, (c) the Pacific Ocean, and (d) the Atlantic Ocean. Negative values of the stream function are shaded and indicate counterclockwise overturning in January. Contour interval for the world ocean is 5 Sv, and the interval for the individual basins is $2.5 \mathrm{~Sv}$.

stress component is antisymmetric across the equator, which was noted by Schopf [1980]. However, this particular aspect of the seasonal wind cycle and its implications for the Ekman transport across the equator do not appear to have been addressed much in the literature, either atmospheric or oceanographic, so further discussion is warranted.

The tropical atmospheric circulation on the largest spatial scales is dominated by the Hadley cell. The dynamics of this circulation have been addressed beginning with Halley [1686] and Hadley [1735]. In more recent times, Gill [1980] proposed a relatively simple model for the atmospheric circulation to illustrate how the tropical atmosphere responds to localized diabatic heating. The circulation that results from the seasonal cycle of heating produces a seasonally varying zonal wind that is antisymmetric across the equator, while the time-mean wind is symmetric across the equator. The reader is referred to Gill [1980] for details, but in summary, he found solutions to the shallow-water equations for the atmosphere on an equatorial beta plane with diabatic heating. These solutions are summarized in Figure 6, showing the zonally averaged meridional stream function together with the surface zonal wind for the time-mean conditions as well as the January and July conditions. The time-mean behavior is given by heating localized along the equator and an atmospheric circulation that is symmetric about it. The January and July conditions are represented by the time-mean solution together with an antisymmetric component in which the maximum heating is in the summer hemisphere. Differencing the January and July conditions gives the zonal wind profile in Figure 7, which is antisymmetric across the equator and in remarkable agreement with Figure 5. In the wind stress climatology 

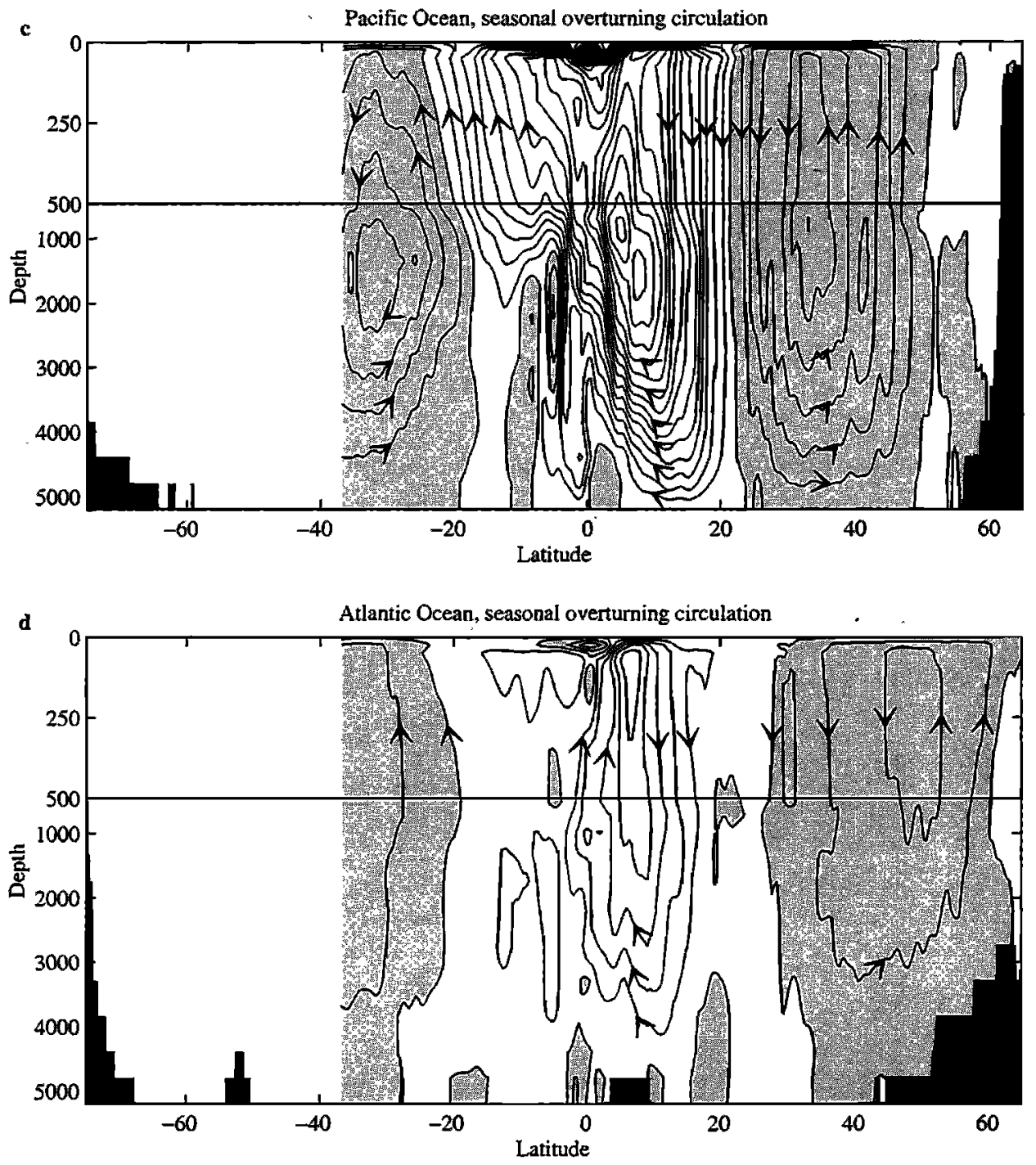

Figure 3. (continued)

the zero crossing of the seasonal cycle occurs at about $23^{\circ} \mathrm{S}$ and $25^{\circ} \mathrm{N}$; in the model of Gill [1980] it occurs at about $24^{\circ}$ (both north and south), assuming a deformation radius of $10^{\circ}$ at the equator. Therefore the Gill [1980] model readily explains this observed characteristic of the seasonal wind field.

As the seasonal cycle in zonal wind is antisymmetric about the equator, its value is zero right at the equator. Since the Coriolis parameter is antisymmetric about the equator as well, the Ekman transport, which is given by their ratio, will be symmetric across the equator. In particular, the seasonal cycle of the Ekman transport is well defined even very near the equator. The seasonal cycle of the zonal wind goes to zero at $\pm 20^{\circ}$ and is of opposite sign poleward of that. This leads to a reversal of the direction of the Ekman transport and a convergence (divergence) there in the winter (summer) hemisphere. Comparing the ocean basins, the seasonal cycle of the zonal wind is weakest in the Atlantic, where it is noticeably weaker south of the equator compared with north of it. This accounts for the marked asymmetry of the seasonal cycle in meridional overturning circulation in the Atlantic (Figure 3). In the Indian Ocean, there is a particularly strong seasonal cycle in the meridional wind associated with the monsoonal system there.

The evidence so far points to a seasonal overturning circulation driven by the wind stress, creating an Ekman layer at the surface, but what of the return flow? In the papers by Kraus and Levitus [1986], Levitus [1987], Adamec et al. [1993], and Ghirardelli et al. [1995], in the Eulerian view, the return flow for the Ekman layer has been assumed to be depth independent. Is this correct, though, and if so, what are the dynamical balances associated with it?

\subsection{The Ocean's Adjustment to Variable Wind Stress}

While some of the investigations of the ocean's seasonal cycle have mentioned a theoretical basis for their work, none have proffered an actual mechanism for the seasonal cycle in the overturning. In particular, the often cited work of Willebrand et al. [1980] argues that the 

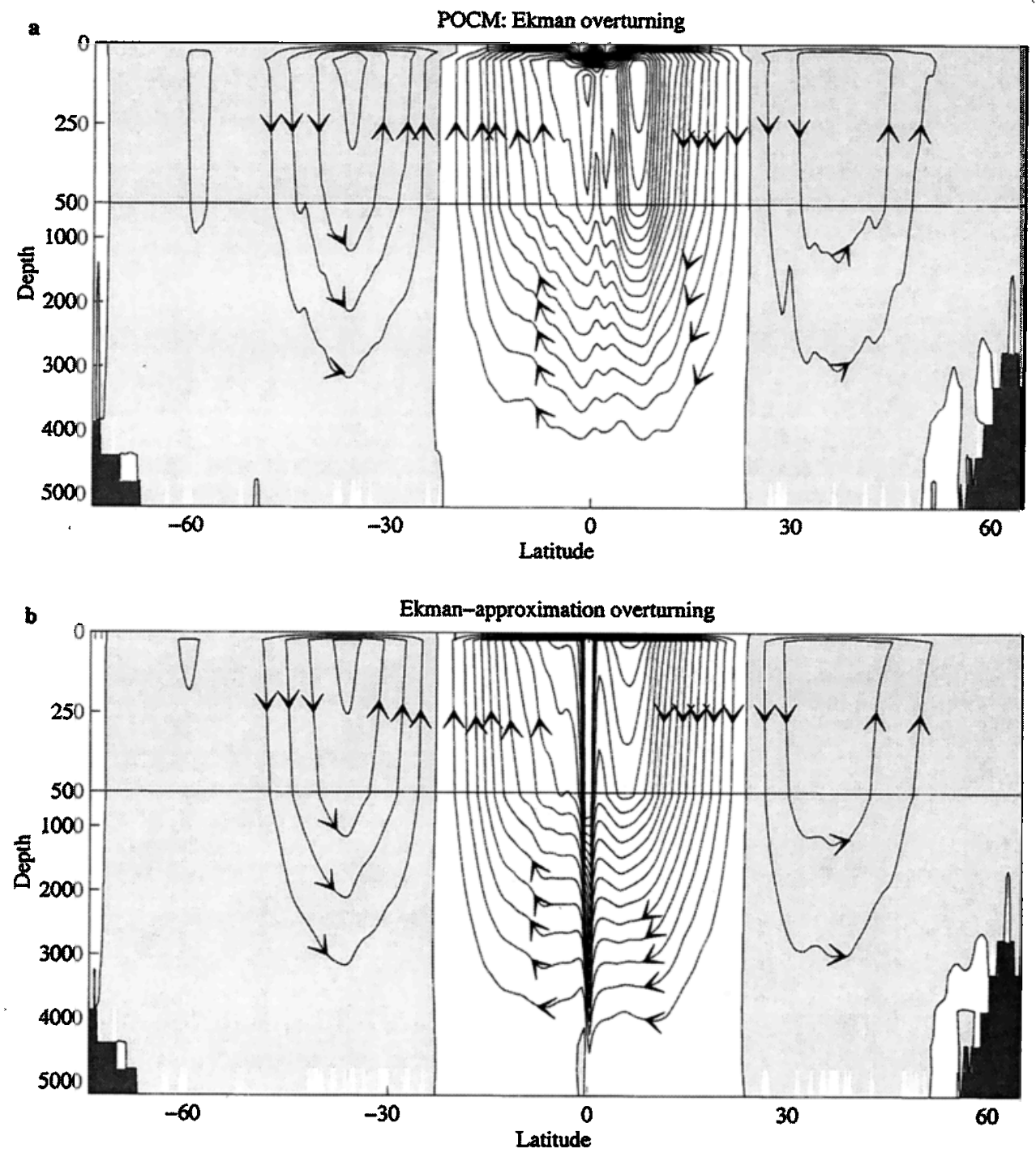

Figure 4. Seasonal (January-July) overturning circulation for the world ocean from (a) the "Ekman only" part of the Parallel Ocean Climate Model (POCM) circulation from equation (2), and (b) the Ekman contribution alone from equation (3). Contour interval is $5 \mathrm{~Sv}$. Negative values of the stream function are shaded and indicate counterclockwise overturning.

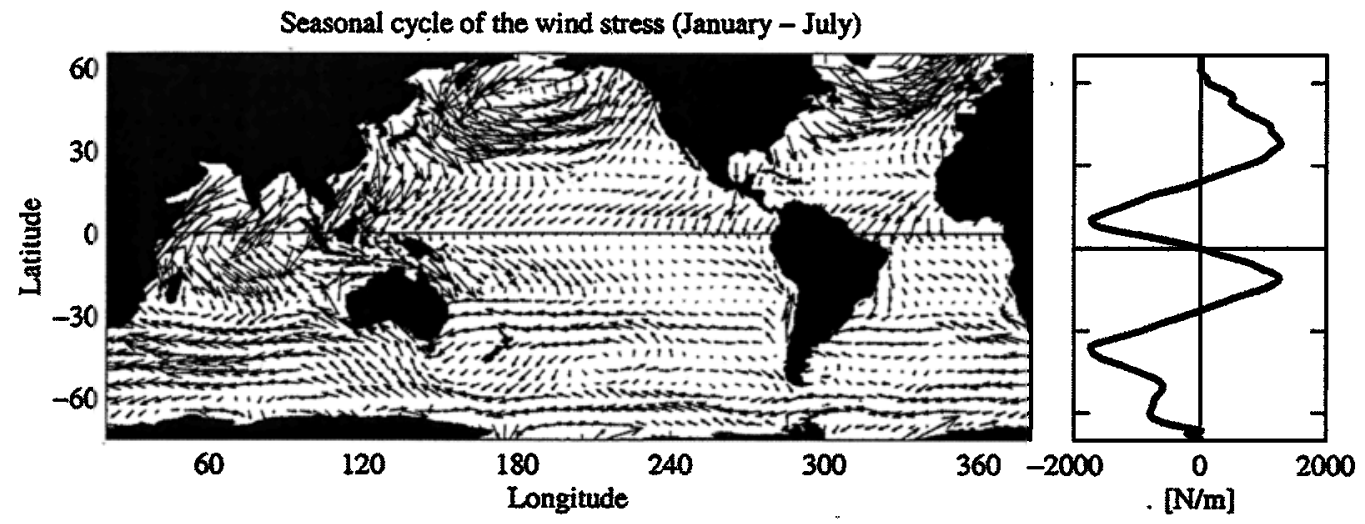

Figure 5. Seasonal cycle (January conditions minus July conditions averaged over the years 1988-1997) of the wind stress, with the zonally integrated zonal wind stress. 

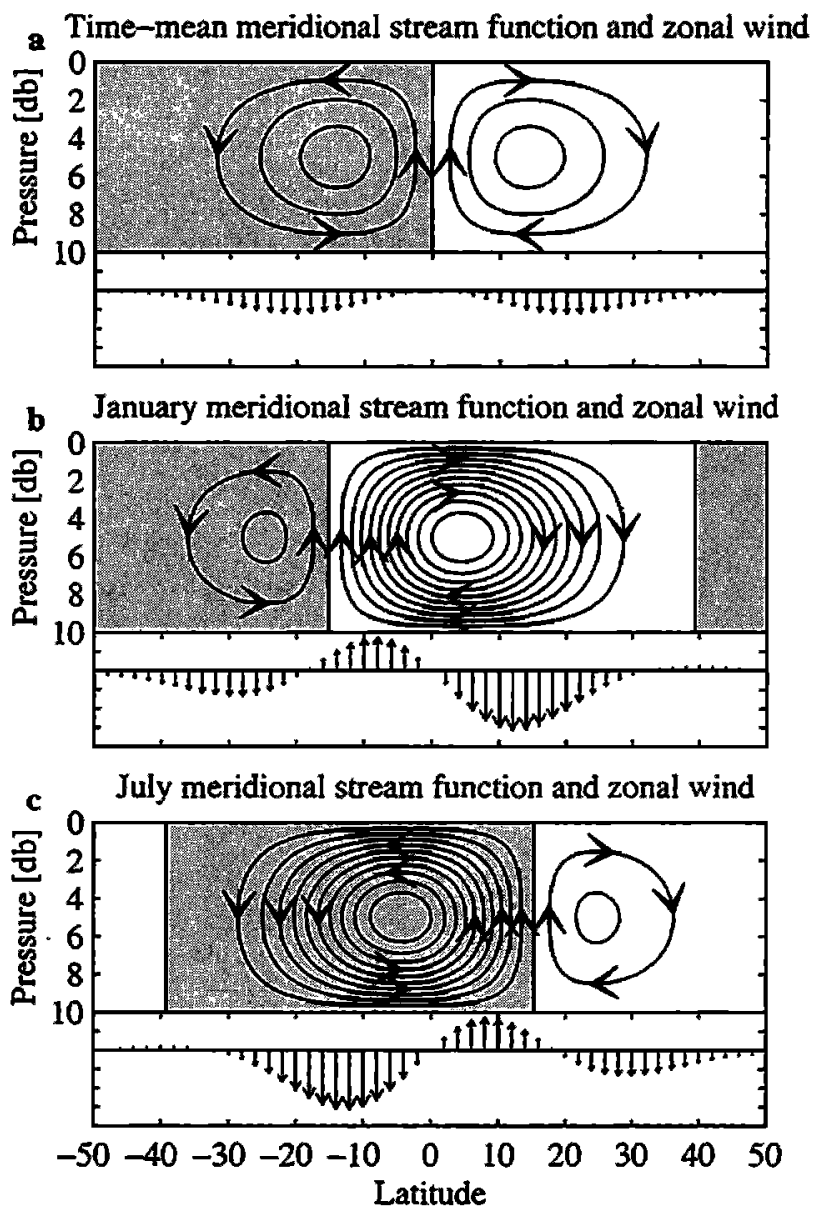

Figure 6. (a) The zonally averaged meridional stream function (upper panel) and the zonally averaged zonal wind (lower panel) for the time-mean tropical atmospheric circulation, (b) the same, but for January conditions, and (c) the same, but for July conditions. Negative values of the stream function are shaded and indicate counterclockwise overturning. Solutions derived from Gill [1980].

Predicted seasonal cycle of the zonal wind

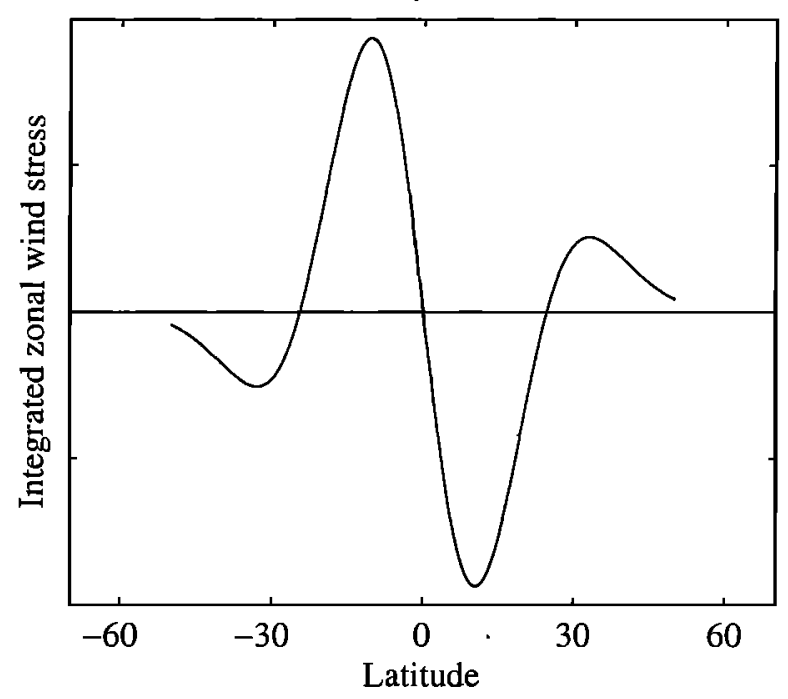

Figure 7. Annual cycle of the zonal integral of the zonal wind stress (January-July) predicted by the Gill [1980] model. ocean response to basin-scale forcing on the timescale of a year should be largely barotropic. However, the connection to the seasonal overturning circulation is not obvious, and moreover, the models used by Willebrand et al. [1980] explicitly excluded the physics that drives the ocean heat transport.

Expanding the work of Philander [1978] on the structure of forced oceanic waves, Willebrand et al. [1980] discussed the ocean response to forcing at large spatial scales, not only by atmospheric wind stress disturbances, but also by surface pressure forcing and a surface mass flux, over timescales from the inertial period to a year. They based their conclusions on the theoretical vertical trapping scale $z_{e}$ of the ocean's forced wave response that satisfies

$$
\int_{-z_{e}}^{0}\left[\left(k^{2}+\frac{\beta k_{x}}{\omega}\right) \frac{N^{2}(z)}{f^{2}-\omega^{2}}\right]^{1 / 2} d z=1
$$

where $\beta$ is the meridional derivative of the Coriolis parameter, $f$ is the Coriolis parameter, $N$ is the BruntVäisälä frequency, $\omega$ is the forcing frequency, and $k=$ $\left(k_{x}, k_{y}\right)$ is the wave number of the forcing. In the limits of $\omega \rightarrow f$ and $\omega \rightarrow 0$, the ocean response becomes strongly surface trapped, that is, $z_{e}$ is much less than the ocean depth. This is also the case for small-wavelength forcing, $k \gg 2 \pi /(100 \mathrm{~km})$. However, the trapping depth increases with increasing horizontal spatial scale and for periods between the time mean and inertial. Away from the equator, for spatial scales larger than 100 $\mathrm{km}$ and between periods of 1 and 300 days, the trapping depth is larger than $5000 \mathrm{~m}$. For the largest spatial scales (the ocean basin scale), the frequency of the forcing can be as low as a year and the trapping depth is still larger than $5000 \mathrm{~m}$. The trapping depth increases with latitude away from the equator and increases for larger basin widths, but it is only a weak function of these two parameters. The theory says that some aspect of the ocean response should be barotropic, but what then is the mechanism by which this happens? Specifically, how does the quasi-geostrophic theory of Willebrand et al. [1980] apply to the seasonal overturning circulations, which are largely driven by nongeostrophic Ekman dynamics?

In the deep ocean, external gravity waves are fast; in water $4000 \mathrm{~m}$ deep, they can travel $17,000 \mathrm{~km}$ per day. Therefore they permit an adjustment to the wind stress across the ocean basin on timescales as short as 1 day. The barotropic adjustment is most readily explained with the following thought experiment. In a Northern Hemisphere basin a zonal wind from east to west is turned on (Figure 8a). Within an inertial period this results in an Ekman transport to the right of the wind, in this case northward. Water then piles up in the northern part of the basin while removing it from the southern part (Figure 8b). This creates a meridional pressure gradient, which drives a flow to its right, east to west 


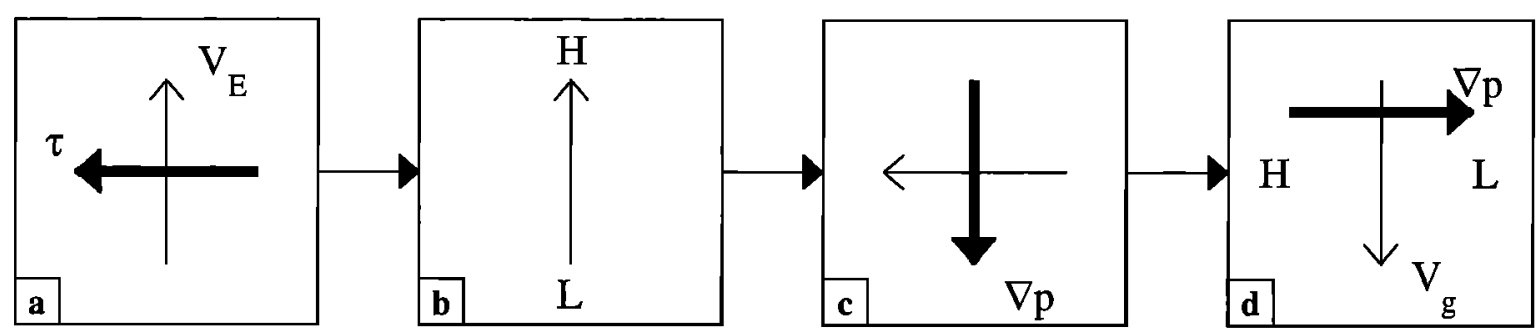

Figure 8. Cartoon of a thought experiment as discussed in text. Forces are represented as bold arrows, and transports are represented as thin arrows. Highs and lows of surface elevation are represented as $\mathrm{H}$ and $\mathrm{L}$, respectively, the wind stress is denoted by $\tau$, the pressure gradient is denoted by $\nabla_{p}$, the Ekman transport is denoted by $V_{E}$, and $V_{g}$ is the geostrophic transport.

(Figure 8c). In turn, water piles up along the western edge of the basin, creating a zonal pressure gradient directed from west to east (Figure 8d). Finally, this zonal pressure gradient drives a geostrophic flow from the north to the south, balancing the Ekman transport and reducing the north-south pressure gradient. In equilibrium, the Ekman transport associated with the wind stress is balanced by the geostrophic transport due to the zonal pressure gradient. This thought experiment is summarized in the cartoon in Figure 8. As the period of the wind stress fluctuation becomes longer, the Ekman layer convergences can couple to the slower internal gravity waves, allowing the ocean response to become baroclinic. However, at basin scales, this only happens at timescales of longer than a year.

A complementary argument for the barotropic compensation of Ekman mass transports caused by largescale wind stress fluctuations comes from Ponte and Rosen [1994] in the context of angular momentum dynamics. In studies of the Earth's angular momentum balance, it has been observed that on timescales as short as 2 weeks, there is a high correlation between the atmospheric angular momentum changes and the observed changes in the length of the Earth's day [Rosen et al., 1990] and polar motion [Ponte et al., 1998]. These results imply that the momentum imparted to the ocean by wind stress is passed through to the solid Earth very quickly. It is readily shown that the following two statements are equivalent: (1) The angular momentum received from the atmosphere by the ocean is transferred completely to the solid Earth, and (2) there is complete compensation of Ekman mass transport by geostrophic barotropic motion. Therefore the angular momentum observations confirm the model's near-perfect compensation between Ekman and geostrophic mass transports.

\subsection{The Equator}

The arguments given above hold over most of the ocean, but the equator requires special discussion. Near the equator, as the Coriolis parameter goes to zero, the vertical trapping scale of forced motion according to (4) becomes very small. However, the argument of Willebrand et al. [1980] is based on quasi-geostrophy that is not valid near the equator. Schopf [1980], in a very idealized study, specifically discussed the role of Ekman flow in the cross-equatorial heat transport, which he found to be unidirectional across the equator. His explanation for this was that at the equator, though the Coriolis force vanishes, the flow is carried across the equator by continuity and direct pressure driving. In the one-hemisphere model of Schopf [1980] the meridional flow was required to be symmetric across the equator by the boundary condition at the equator, namely, that $\partial v / \partial \phi=0$, where $v$ is the meridional velocity and $\phi$ is the latitude. However, in the global model used here, that requirement is not explicitly imposed. Rather, it is created by the antisymmetry of the seasonally varying zonal winds about the equator, which implies that the seasonally varying, meridional Ekman transport, where it is defined, is symmetric about the equator. By continuity, any deviation in the flow from symmetry close to the equator would tend to pile water up on one side or the other; but with the vanishing Coriolis parameter there, nothing could support the pressure gradient and the water would be pushed directly down the pressure gradient.

Figure 3 shows that within $\pm 2^{\circ}$ of the equator, there is a very shallow circulation trapped at the surface that is directly driven by the meridional wind. It is largest in the Indian Ocean where the seasonal cycle of the crossequatorial meridional wind is the strongest. It is also present in the Pacific Ocean and to a much smaller extent in the Atlantic Ocean. Figure 9 shows an expanded view of the POCM's seasonal equatorial circulation in the Indian Ocean. This "roll" circulation was discussed in the study of the Indian Ocean by Wacongne and Pacanowski [1996], who found that it was frictionally driven in the downwind direction. Furthermore, they stated that it did not affect the meridional heat transport, as it was simply recirculating water of the same temperature. This circulation feature can also be seen in the model-based studies by Garternicht and Schott [1997] and Lee and Marotzke [1998]. The strong vertical shear needed by this flow can only occur near the equator since the thermal wind constraint does not apply there. 
Indian Ocean, seasonal overturning circulation

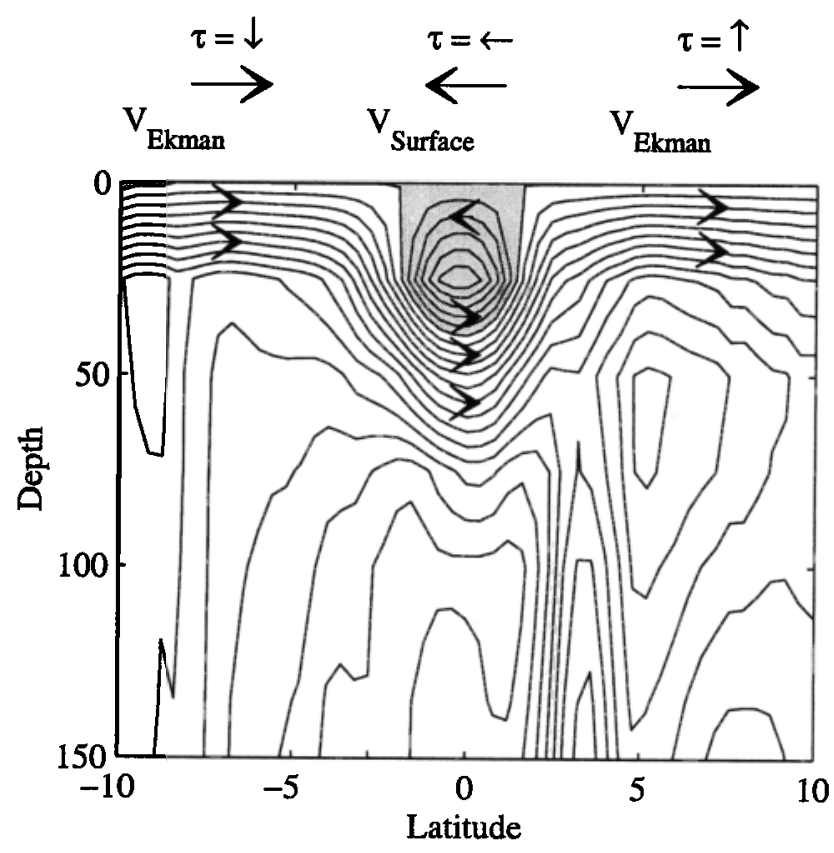

Figure 9. Close-up of seasonal equatorial circulation in the Indian Ocean. Contour interval is $2.5 \mathrm{~Sv}$. Negative values of the stream function are shaded. The wind stress $\tau$ is denoted by arrows; up arrows are into the page (east to west), down arrows are out of the page (west to east), and left arrows are north to south.

\subsection{Summary of the Ocean's Response to Time- Varying Wind Stress}

All components of a complete theory of the role of wind forcing in driving heat transport variations can now be brought together. An oscillation in the zonal integral over the basin width of the zonal wind stress drives a corresponding change in the integrated northward Ekman mass transport across that section. This response of the Ekman transport to the variable wind occurs quickly, on the timescale of an inertial period. The change in the mass transport across the zonal section creates a pressure imbalance that through geostrophy and a series of gravity waves adjusts the pressure gradient to drive a barotropic flow back across the section, balancing the initial change in the Ekman transport. Hence there is no net flow across the section. The response is essentially the combination of the wind stress leading to an Ekman mass transport, coupled with a compensating flow governed by barotropic dynamics of the kind discussed by Willebrand et al. [1980]. Near the equator, where the Coriolis parameter goes to zero, the symmetry of the flow field around the equator and continuity create a pressure gradient to directly drive the flow across the equator. The temperature difference between the Ekman layer and the section-averaged temperature coupled with the opposite directions of the flows creates a heat transport across the section. The depth indepen- dence of the time-varying flow means that it will not appear in velocity fields computed from density fields taken from one-time hydrographic surveys. An important conclusion from this is that estimates of the timemean ocean circulation from hydrographic surveys will not be contaminated by the aliasing of this signal, as long as the time-mean wind stress is used in the calculation.

\section{RELATIONSHIP BETWEEN THE WIND AND HEAT TRANSPORT}

In the section 3 the dynamics of the seasonal changes in the ocean circulation were discussed. In this section it will be shown how those changes in circulation affect the ocean heat transport. In section 5 the modeled heat transport variability will be compared with prior estimates and the impact of the variability on hydrographic estimates of the time-mean heat transport will be discussed.

\subsection{Definitions}

Using the output from POCM, the ocean heat transport across latitude lines was calculated every 3 days for the period 1988-1997. The heat transport for a Boussinesq, incompressible fluid is

$Q(t)=\rho_{0} c_{p} \iint v \theta d z d x-\rho_{0} c_{p} M(y)\langle[\theta]\rangle(y)$,

where $Q(t)$ is the heat transport, $x$ is the zonal coordinate, $z$ is the depth coordinate and $t$ is time, $\rho_{0}$ is the density of seawater, here set to be $1025 \mathrm{~kg} \mathrm{~m}^{-3}$, and $c_{p}$ is the specific heat of seawater, $3994 \mathrm{~J} \mathrm{~kg}^{-10} \mathrm{C}^{-1}$. The model meridional velocity is $v(x, y, z, t)$, and its zonal integral gives the total mass transport across the section, $M(y)=\iint v d z d x$. The model temperature is $\theta(x, y$, $z, t)$, and its zonal section average is given by $\langle[\theta]\rangle(y)=$ $\iint \theta d z d x / \iint d z d x$.

Like the real ocean, this numerical model has a free surface, so at any given time there may be a nonzero mass transport through a section. This presents a conceptual and practical problem, as the prescription of the heat or energy transport requires zero net mass transport through the chosen boundary to eliminate arbitrary reference state constraints. The net movement of water across a zonal section does not necessarily represent a climatologically important energy transport, as it may simply move back across the section at a later time. The second term in (5) accounts for the instantaneous, nonzero net mass transport across the section and recovers the temperature-scale independence for the heat transport calculation. This term has a negligible overall effect on the estimate of the heat transport if the time-mean mass transport across the section is nearly zero and the time-dependent portion of the section-integrated mass transport is uncorrelated with the mean zonal temperature deviations. In the model this adjustment has a 
maximum root-mean-square amplitude of $0.04 \mathrm{PW}$ near the equator, compared with the total heat transport that has a root-mean-square variability of $4 \mathrm{PW}$ there. Therefore it is a small part of the much larger signal and will not be discussed further. There is, however, a particular area of the ocean where the definition of heat transport in (5) is still not sufficient: the latitudes south of the Indo-Pacific throughflow.

For zonal sections in the Indian and Pacific Oceans south of the Indo-Pacific throughflow, the time-mean mass transport is not small and calculating individual basin heat transports is conceptually more difficult. However, it is still desirable to discuss each basin's heat transport independently and not combined, as usually has been done [e.g., Semtner and Chervin, 1992]. In particular, it is desirable to calculate the net heating or cooling experienced by the net mass transport while it traverses the South Indian or South Pacific. Equation (5), by eliminating contributions from a net mass transport altogether, does not permit this computation, but Zhang and Marotzke [1999] proposed a method for accounting for the local warming (or cooling) of the water that has entered into the basin from the Indo-Pacific throughflow, while keeping the result independent of the temperature scale chosen. For zonal sections affected by the Indo-Pacific throughflow in the Indian Ocean, (5) is modified to still represent the complete divergent part of the heat transport, denoted $Q_{\mathrm{div}}$ :

$Q_{\mathrm{div}}(t)=Q(t)+\rho_{0} \mathcal{C}_{p} M(y)\left(\langle[\theta]\rangle(y)-\left\langle\left[\theta_{I}\right]\right\rangle\right)$,

where $\left\langle\left[\theta_{I}\right]\right\rangle$ is the section mean temperature of the throughflow transport. The sign of the correction term is reversed for Pacific Ocean sections. In the POCM, there are four gaps resolved in the Indo-Pacific throughflow region, and therefore the flow through all of them must be accounted for individually; this is done for each time point and for all latitudes south of the throughflow. A thorough discussion of the Indonesian throughflow based on observations and model analysis of the $1 / 6^{\circ} \mathrm{Los}$ Alamos Parallel Ocean Program (POP) model [Dukowicz and Smith, 1994; Fu and Smith, 1996; Maltrud et al., 1998] is given by Gordon and McClean [1999]. Since these models are so similar in design and forcing, and our results are very similar to theirs, the throughflow will not be discussed further.

\subsection{Temporal Variability}

Heat transport in POCM was calculated for each basin using (5) and (6). The annual cycles are summarized in Figure 10. The largest signal is confined to within $20^{\circ}$ of the equator and is in phase across the equator. For the world ocean total, the annual cycle near the equator has an amplitude of nearly $6 \mathrm{PW}$ peak to peak. This is composed of annual cycles in the Indian Ocean of 2.6 PW peak to peak, $3 \mathrm{PW}$ peak to peak in the Pacific Ocean, and a much weaker annual cycle in the Atlantic Ocean of about $1 \mathrm{PW}$. The Indian Ocean's

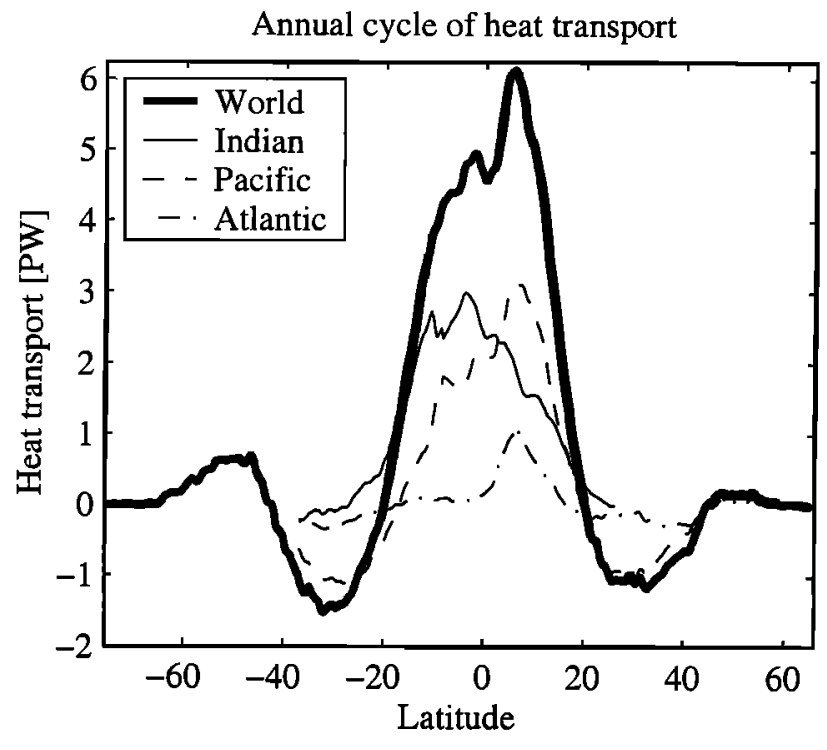

Figure 10. Annual cycle of heat transport defined as the difference between January and July values for the world ocean (bold curve), the Indian Ocean (thin solid curve), the Pacific Ocean (dashed curve), and the Atlantic Ocean (dashdotted curve).

annual cycle has a peak at $5^{\circ}$ S, while the Atlantic and Pacific Ocean peak amplitudes are at $7^{\circ} \mathrm{N}$. The seasonal heat transport variability is much larger than the time mean of around 1-2 PW. The ocean response to the seasonal cycle in the atmospheric wind stress is to transport heat from the summer hemisphere to the winter hemisphere, in phase with the total energy transport by the atmosphere's Hadley cell [Peixoto and Oort, 1992].

To examine the high-frequency variability of the global ocean heat transport variability, a Hovmöller diagram of the heat transport anomaly as a function of latitude and time is presented for the world ocean (Plate 1). To highlight the variability, the time-mean heat transport was removed from the time series, and it was filtered in time using a simple triangle filter of half width 4.5 days to reduce the amplitude of aliased inertial oscillations [Jayne and Tokmakian, 1997]. The variability is dominated by a large annual cycle, and the largest signal is confined to within $20^{\circ}$ of the equator and is in phase across the equator. Superimposed on the annual cycle are both higher-frequency oscillations and interannual variations that are coherent over large meridional extents. In particular, there are short-term heat transport fluctuations near the equator that completely compensate the "seasonal" signal. Heat transports in the subtropical gyres are weaker and of opposite sign, compared with the tropics, which further enhance a midlatitude heat transport convergence in the winter hemisphere and a net divergence in the summer hemisphere relative to the time mean.

A final discussion of the tropics is in order, as the picture there is not intuitively obvious and the seasonal cycles of heat transport by both the atmosphere and 


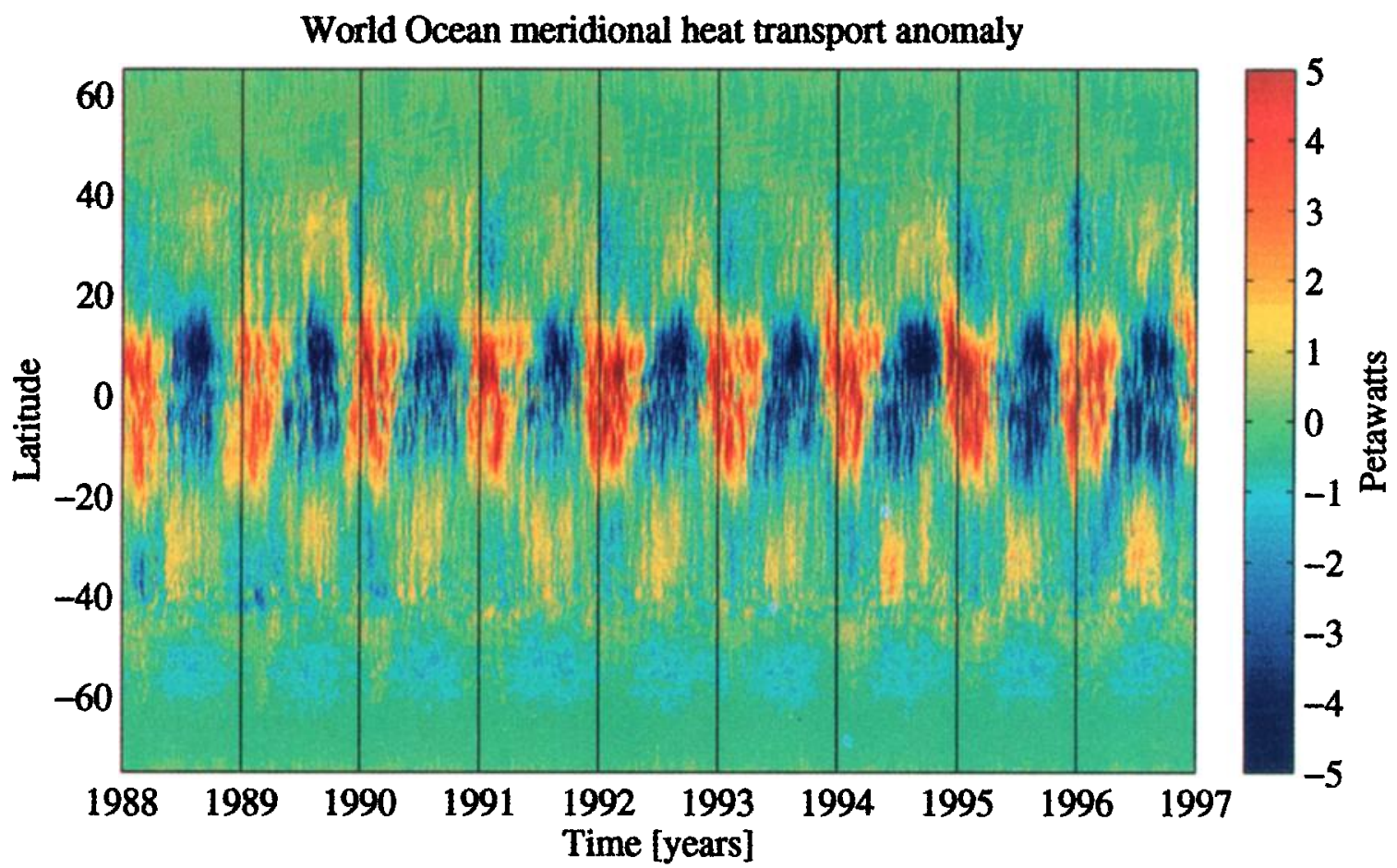

Plate 1. Time-dependent heat transport anomaly for the world ocean. The time-mean heat transport has been removed to highlight the variability. Vertical lines mark January 1.

ocean are very strong there. In January (Northern Hemisphere winter) the area of maximum heating is in the Southern Hemisphere. In July the anomaly circulation in the atmosphere is reversed as the latitude of maximum heating moves into the Northern Hemisphere. The resulting anomaly in the atmospheric circulation has a net energy transport from the summer hemisphere into the winter hemisphere. The sensible and latent heat transports are directed from the winter hemisphere into the summer hemisphere, but the potential energy is directed from the summer hemisphere into the winter hemisphere and overcompensates for the sensible and latent heat transports so that the net atmospheric energy transport is from the summer hemisphere into the winter hemisphere [Peixoto and Oort, 1992]. The ocean's heat transport anomaly is likewise directed from the summer hemisphere into the winter hemisphere. So in total, the atmosphere and ocean together undergo a combined seasonal energy transport of $\pm 4.5 \mathrm{PW}$ across the equator, with nearly equal contributions from the atmosphere and ocean.

\subsection{Temporal Decomposition}

As it has been shown that there is large variability in the ocean heat transport, we now ask whether the fluctuations are indeed caused entirely by the changes in the Ekman transports shown in the previous section or if variability in the ocean temperature fields play a role as well. Contributions to the heat transport by time-mean and time-varying circulations and thermal fields are now examined. The heat transport is decomposed as

$$
\begin{aligned}
\frac{Q(t)}{\rho_{0} c_{p}}= & \iint_{-H}^{0} \bar{v} \bar{\theta} d z d x+\iint_{-H}^{0} v^{\prime} \bar{\theta} d z d x \\
& +\iint_{-H}^{0} \bar{v} \theta^{\prime} d z d x+\iint_{-H}^{0} v^{\prime} \theta^{\prime} d z d x
\end{aligned}
$$

where the overbar represents the time mean of the quantity and the prime represents the deviations from it. The first term on the left-hand side of (7) corresponds to the time-mean velocity advecting the time-mean temperature. The second term represents the variations in velocity acting on time-mean temperature, while the third term represents time-mean velocity field advecting variations in temperature. Finally, the fourth term of (7) is the result of variations in both velocity and temperature. Since by definition $\int()^{\prime} d t=0$, the second and third terms of (7) do not contribute to the time-mean heat transport. However, the time mean of the fourth term is not zero but it is small over much of the ocean (see S. R. Jayne and J. Marotzke (The oceanic eddy heat transport, submitted to Journal of Physical Oceanography, 2001) for more details).

To quantify the strengths of the individual contributions of the time-varying components to the total variation of the heat transport shown in Plate 1, the components of (7) can be considered in terms of their fractional covariance. Given a time-varying signal composed of the three components,

$$
Q(t)=A(t)+B(t)+C(t),
$$


- Percentage variance explained by temporal components

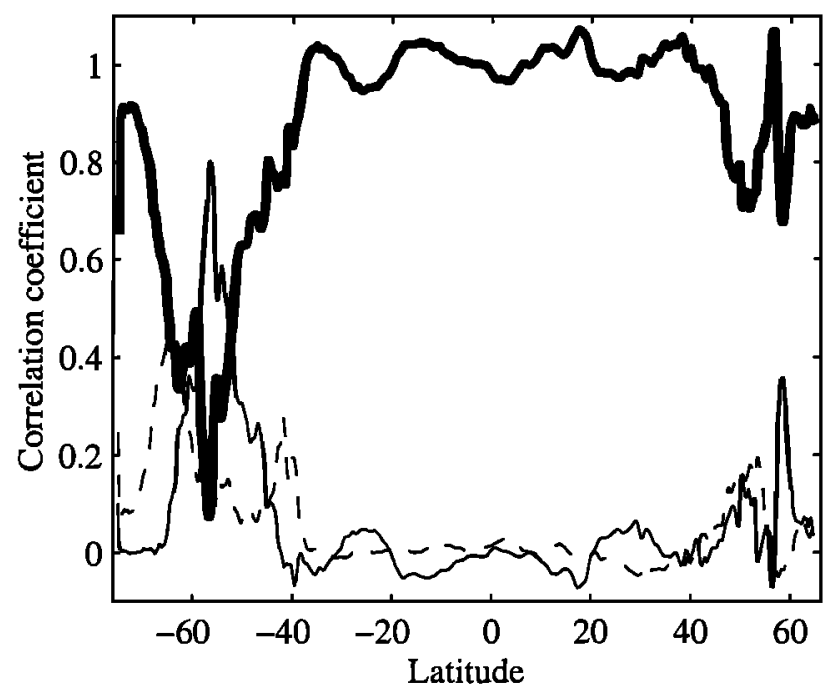

Figure 11. Correlation of each component of the heat transport variability with the total variability: the velocity variations with the time-mean temperature (bold curve), the temperature variations with the time-mean velocity (thin curve), and the covarying velocity and temperature (dashed curve). All three components sum to 1 .

where each component has had its time mean removed, the correlation is computed by

$$
\boldsymbol{\rho}_{A}=\frac{\int Q(t) A(t) d t}{\int Q(t)^{2} d t} .
$$

It is trivial to show that $\rho_{A}+\rho_{B}+\rho_{C}=1$. The correlations of three components of the heat transport variability given in (7) to the total heat transport variability are computed as a function of latitude, and the result is shown in Figure 11 . The velocity variations alone account for a majority ( $70 \%$ and more) of the variability over most latitudes. The exceptions to this are the latitudes between $45^{\circ}$ and $60^{\circ} \mathrm{S}$, where the temperature variations contribute up to $80 \%$ of heat transport variability, suggesting that the seasonal cycle of the thermal forcing is very important in determining the cycle of the heat transport at high latitudes, especially in the Southern Ocean. Overall, the covarying velocity and temperature variations only weakly contribute to the total, except in the Antarctic Circumpolar Current. It is evident from Figure 11 that the heat transport variability is dominated by velocity variations acting on the timemean temperature field and to a lesser extent by temperature fluctuations advected by the time-mean velocity field.

As a final check on our argument that the heat transport variability is dominated by dynamics in the Ekman layer, we compare the annual cycle of the model heat transport decomposed as in (7) with the corresponding decomposition of the Ekman heat transport given by (1). For the sake of simplicity, the estimate of the annual cycle in the Ekman heat transport uses an observational climatology of annually averaged monthly values of ocean temperature [Levitus and Boyer, 1994] and the ECMWF wind stress fields used to force the POCM simulation, reduced to an average annual cycle of monthly values.

First, the portion of the Ekman heat transport variability arising from the temporal variation in the Ekman layer mass transport alone is examined. Figure 12 shows the average annual cycle of the heat transport in POCM owing to velocity variations, given by the second term of (7), compared with the Ekman heat transport variations due to wind stress variability, using (1) with the timevarying part of the wind stress and the time-mean temperature. The seasonal cycle is again taken as January conditions minus July conditions averaged over the last 9 years of the model simulation (1988-1997). The agreement between the heat transport variability in POCM due to velocity variations and this simple calculation shows overall good agreement, which shows that the time-dependent ocean heat transport is essentially given by the time-varying part of the Ekman heat transport. The poorest agreement is in the tropical Indian Ocean, where the seasonal cycle of the meridional winds probably plays a role. This is not an unexpected result given arguments by Bryan [1982] that the meridional wind tends to suppress the heat transport there. It is difficult to add the meridional wind to the calculation given in (1), except in some ad hoc fashion.

Next, we consider the heat transport fluctuations owing to variations in the temperature field given by the third term of (7). For the Ekman heat transport the time-mean wind stress is used with the time-varying part of the Ekman layer temperature in (1). Here the assumption is made that only the temperature variability in the Ekman surface layer is important in driving the variability. The return flow for the time-mean Ekman transport is presumed to be deep enough that its temperature does not vary strongly on timescales shorter than the seasonal. As a result, for this term, no specification of the return flow temperature needs to be made, since it does not contribute to the Ekman heat transport variability. Hence the question of the exact structure of the Ekman layer's return flow is avoided. Figure 13 compares the estimate from the climatological data using the third term of (7) and the output from POCM. The agreement is reasonably good. Of particular note is the seasonal cycle of heat transport in the southernmost latitudes owing to temperature variations in the surface layer (considerably stronger in the model than in the climatological estimate). This was not seen before in the results of Bryan and Lewis [1979] and Bryan [1982], as their model did not include this variability because of a lack of time-varying thermal forcing. 

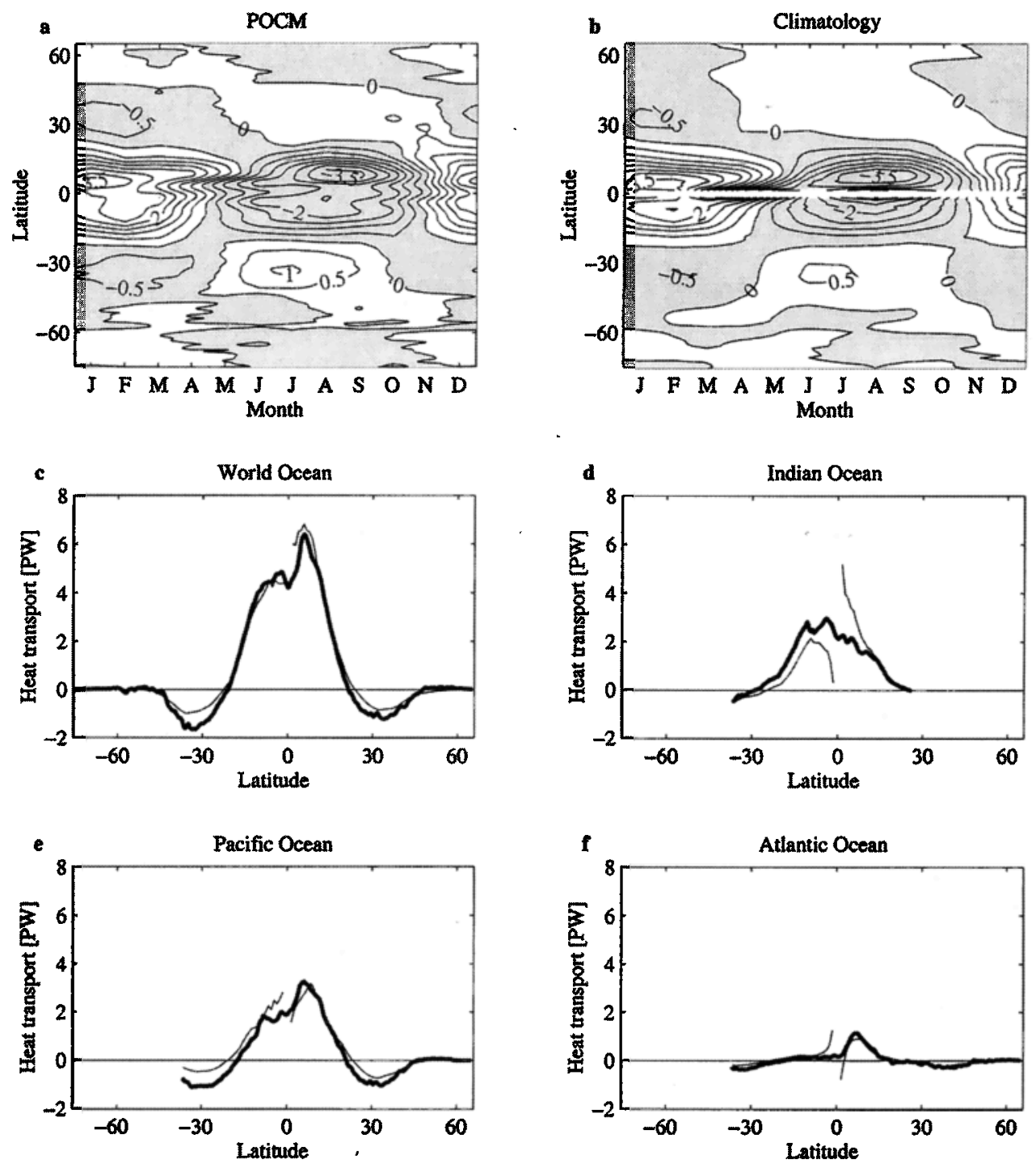

Figure 12. Comparison of annual cycle of heat transport induced by velocity anomalies for the world ocean from (a) the POCM and (b) climatology from the second term of equation (7). Also shown are the annual cycle (January-July) from the POCM (bold curves) versus climatology (thin curves) for (c) the world ocean, (d) the Indian Ocean, (e) the Pacific Ocean, and (f) the Atlantic Ocean. Contour interval for Figures 12a and $12 \mathrm{~b}$ is $0.5 \mathrm{PW}$.

\subsection{Error Estimates}

It is important to consider the error in the model estimation of the heat transport. Errors in a numerical model may come from any number of sources including missing model physics, errors in the boundary conditions, errors in the forcing fields, and deficiencies in the numerical methods used. It is beyond the scope of this work to do a thorough error analysis of the POCM, but some comments are required. Since the seasonal cycle of the wind dominates the dynamics of the ocean heat transport variability, errors in wind stress need to be investigated. Even this simple proposition is difficult, though. No formal error estimate is available for the wind stress data used in this study. An examination of older wind stress climatologies [e.g., Hellerman and Rosenstein, 1983] shows that the error in individual wind stress values is a complex function of space, due mostly to the geographical coverage of the observing stations. Furthermore, the quantity of interest is an integral quantity of the wind stress field. The errors in the wind are presumably wave number dependent, with the longer waves being better resolved by the sampling network. Therefore perhaps the best that can be done is to compare the estimates derived from two different wind stress fields as a proxy for the error. The two wind stress climatologies used here were created from observations over different time periods and hence can be considered independent. The first is the ECMWF wind stress fields used in the POCM run, and the second is the Hellerman and Rosenstein [1983] wind stress climatology.

Figure 14 shows the seasonal cycle (January-July) of heat transport derived from (1) using the wind clima- 

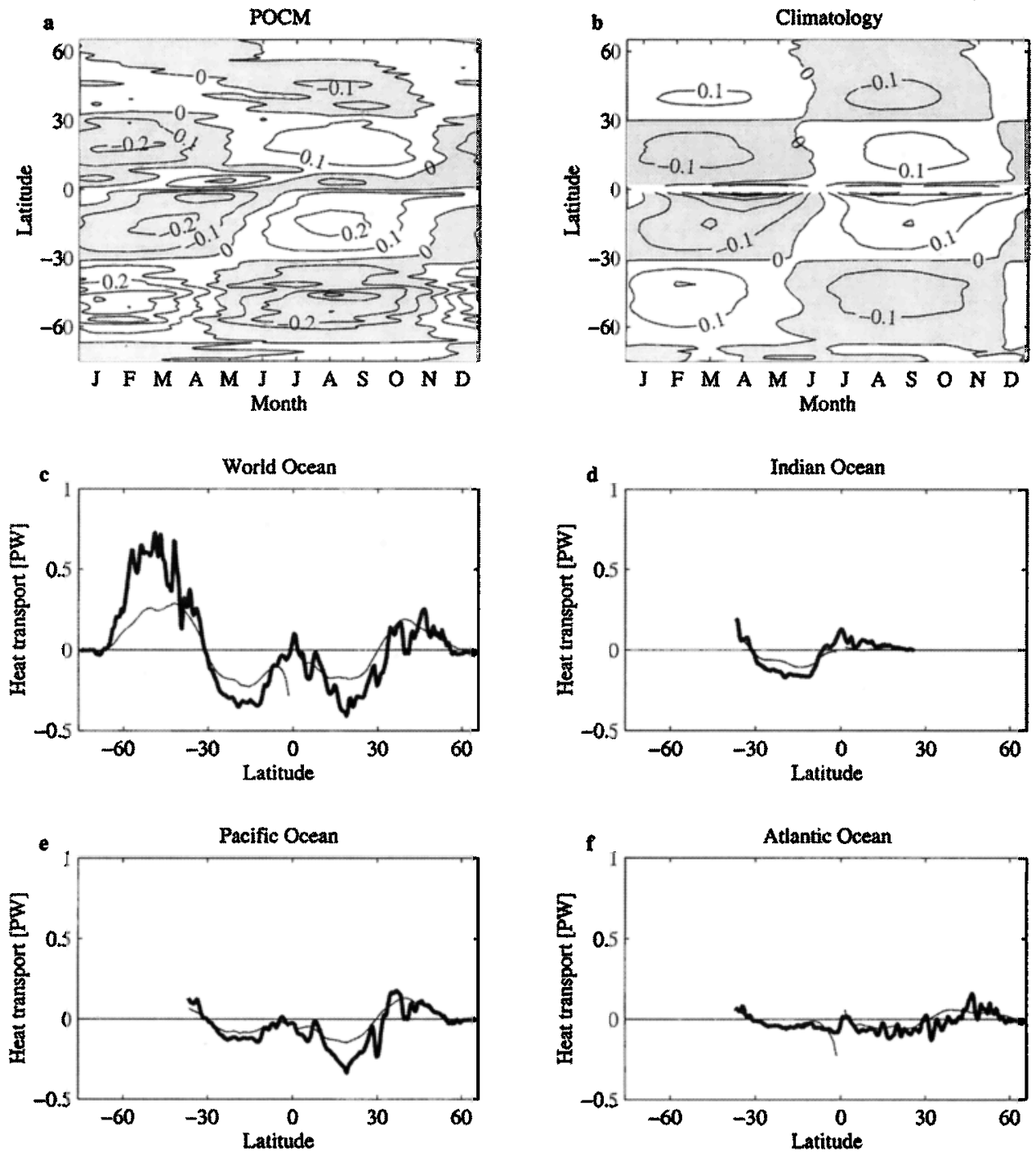

Figure 13. Comparison of annual cycle of heat transport induced by temperature anomalies for the world ocean from (a) the POCM and (b) climatology from the third term of equation (7). Also shown are the annual cycle (January-July) from the POCM (bold curves) versus climatology (thin curves) for (c) the world ocean, (d) the Indian Ocean, (e) the Pacific Ocean, and (f) the Atlantic Ocean. Contour interval for Figures 13a and $13 \mathrm{~b}$ is $0.1 \mathrm{PW}$.

tologies and the Levitus and Boyer [1994] temperature climatology. The estimates agree reasonably well in their spatial distribution and magnitude, with a difference of roughly $1 \mathrm{PW}$. The Hellerman and Rosenstein [1983] climatology gives a larger magnitude for the annual cycle than the newer ECMWF climatology. This is particularly true near the equator, where the smallness of the Coriolis parameter amplifies differences between them and the uncertainty is at least $2 \mathrm{PW}$.

\section{IMPACTS OF HEAT TRANSPORT VARIABILITY}

In this section we step back from the dynamics that create the ocean's heat transport variability and consider the broader picture. In particular, the POCM's seasonal cycle of heat transport is directly compared with previous studies [Bryan and Lewis, 1979; Carissimo et al., 1985; Hsiung et al., 1989]. The overall seasonal heat budget is examined, and finally, the impact of the variability on the estimation of the time-mean ocean heat transport from one-time hydrographic surveys is considered.

\subsection{Comparison With Previous Model and Observational Results}

Bryan and Lewis [1979] used a numerical model of the global ocean, forced with monthly averaged wind stresses from Hellerman [1967], and restored to timemean sea surface temperature fields of Levitus and Oort [1977]. Their annual cycle in heat transport, taken as the January minus July transports, is shown in Figure 15, 

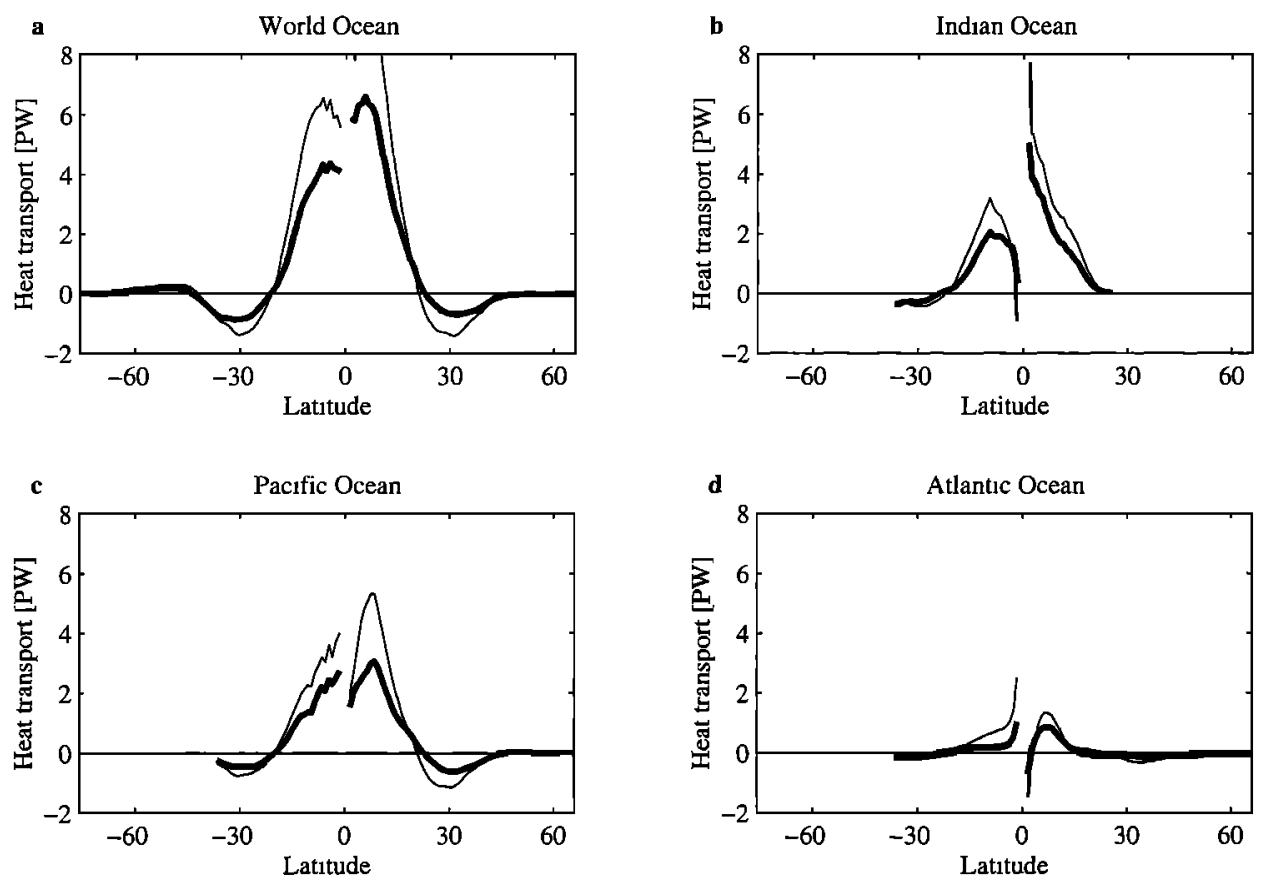

Figure 14. Comparison of Ekman heat transport (January-July) predicted from the European Centre for Medium-Range Weather Forecasts (bold curves) versus Hellerman and Rosenstein [1983] climatology (thin curves) for (a) the world ocean, (b) the Indian Ocean, (c) the Pacific Ocean, and (d) the Atlantic Ocean.

contrasted with the same annual cycle of heat transport from the POCM 4_B run (and some observations-based estimates; see below). The model estimates are remarkably similar given that the POCM simulation was forced with higher-quality and higher-frequency wind stresses

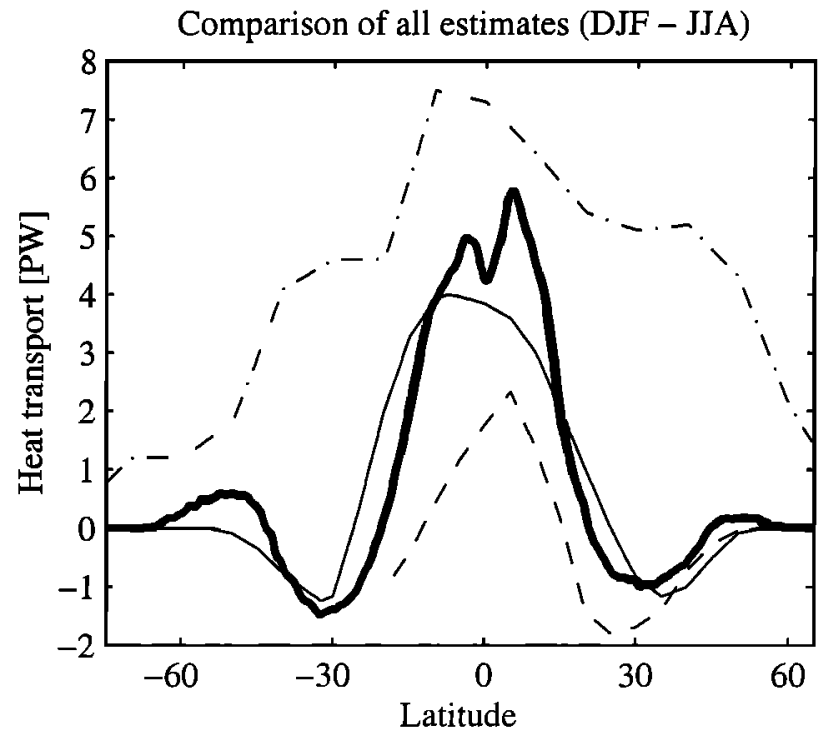

Figure 15. Comparison of the annual cycle of ocean heat transport for the world ocean from POCM (bold curve), the numerical model of Bryan and Lewis [1979] (thin solid curve), Hsiung et al. [1989] (dashed curve), and Carissimo et al. [1985] (dash-dotted curve). Note that all estimates are for DecemberJanuary-February minus June-July-August, except for Bryan and Lewis [1979], which is for January-July conditions. in addition to time-varying thermal forcing in POCM. There are, however, differences. POCM has a largeramplitude annual cycle, particularly in the tropics north of the equator. While the Bryan and Lewis [1979] estimate is nearly symmetric about the equator, the POCM is less so. In addition, POCM has a decrease in the heat transport annual cycle at the equator that is not present in the Bryan and Lewis [1979] model. This double peak in the world total in the POCM arises from the Pacific and Atlantic having their peak annual cycles at $7^{\circ} \mathrm{N}$ while the Indian Ocean has its peak at $5^{\circ} \mathrm{S}$. Presumably, its appearance is due to differences and improvements in the wind stress fields used by the POCM. Also, the POCM simulation has a significant seasonal cycle at the southernmost latitudes where Bryan and Lewis [1979] have none. It was shown above that this is an effect of the time-varying thermal forcing that was absent in the Bryan and Lewis [1979] work.

Carissimo et al. [1985] used satellite-derived net radiation balances, atmospheric transports, and ocean heat storages to estimate the ocean heat transport as a residual. Their annual cycle, as measured by the difference in the season of December, January, and February minus the season of June, July, and August, is likewise presented in Figure 15. There are large differences between the POCM heat transport and the Carissimo et al. [1985] estimate. While the POCM annual cycle changes sign in the midlatitudes and then again at high latitudes, the Carissimo et al. [1985] estimate does not and is of the same sign over the whole latitudinal extent. However, it is difficult to say what differences are significant, as 


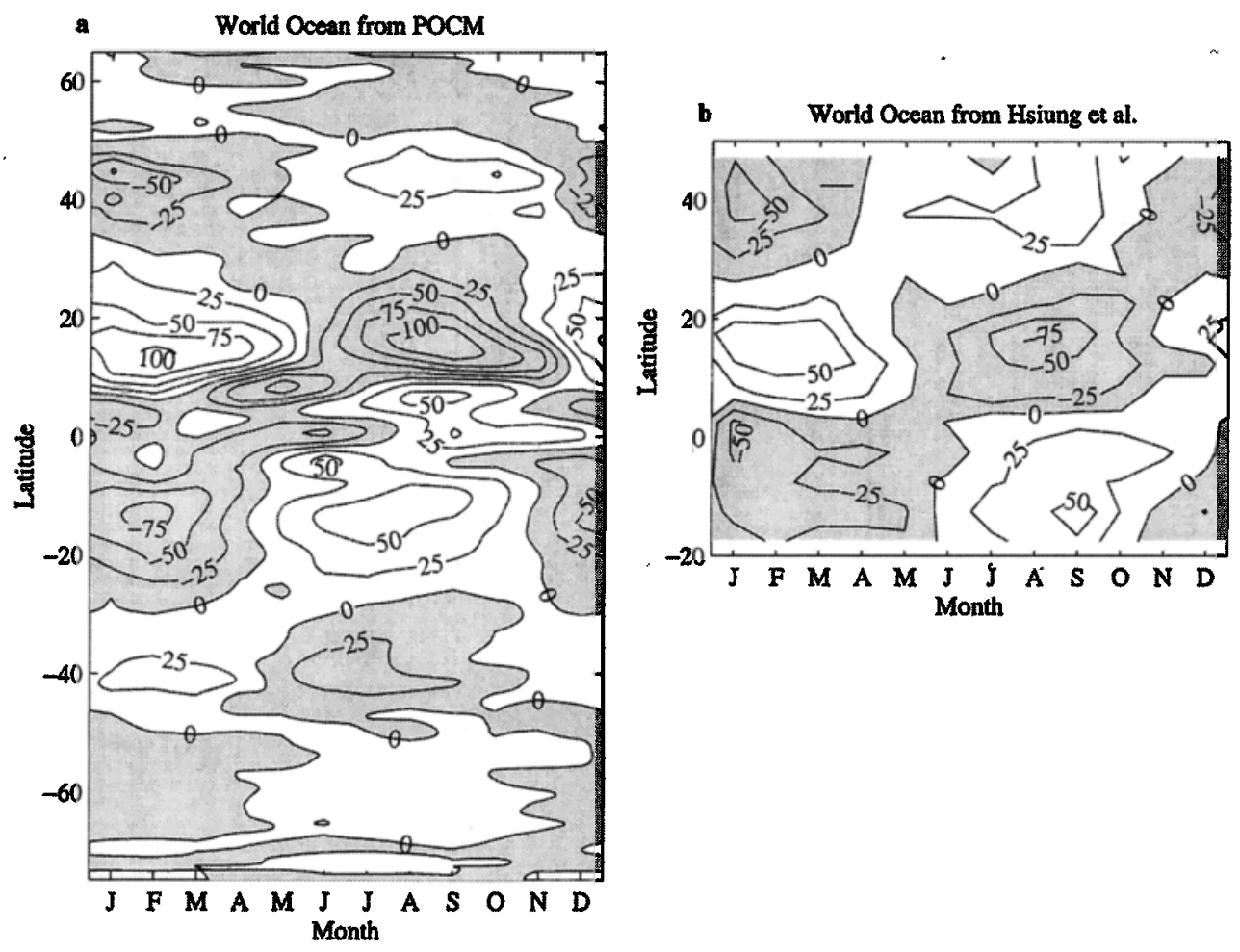

Figure 16. Annual cycle of the divergence of the advective ocean heat transport (time-mean removed) for the (a) world ocean from POCM and (b) Hsiung et al. [1989]. The contour interval is $25 \mathrm{~W} \mathrm{~m}^{-2}$; shading indicates negative fluxes.

the estimated error of Carissimo et al. [1985] is \pm 3 PW, which may still be too small given that their estimate is inconsistent with observations by Hsiung et al. [1989], Bryden et al. [1991], and Trenberth and Solomon [1994].

Hsiung et al. [1989] expanded the work of Lamb and Bunker [1982] to include the Pacific and Indian Oceans as well as the Atlantic Ocean. For their estimate of the heat transport, Hsiung et al. [1989] used ocean heatstorage observations combined with ocean surface heat fluxes derived from the bulk formulae to calculate the ocean heat transport as the residual. They estimated monthly values of the heat transport for each of the three basins between $50^{\circ} \mathrm{N}$ and $20^{\circ} \mathrm{S}$. Errors in their data analysis tended to accumulate as they integrated from north to south so that the transports near the equator were unreliable and compared poorly with other estimates of the transport [e.g., Philander and Pacanowski, 1986; Böning and Hermann, 1994]. Figure 15 shows that the annual cycle estimated by Hsiung et al. [1989] is much weaker than in the other cases. Therefore a comparison of the divergence of the heat transport from POCM with their more robust estimate of the divergence is made in Figure 16. This allows two things: First, any systematic errors are removed by the differentiation, and second, we can present the annual cycle of world ocean heat transport divergence from POCM, which is more directly relevant to climate. The estimate of Hsiung et al. [1989] and the estimate derived from POCM are gener- ally similar. In agreement with the Bryan and Lewis [1979] estimate, the annual cycle of Hsiung et al. [1989] changes sign in the midlatitudes. The range of the error bars on the Hsiung et al. [1989] estimate is $\pm 25-50 \mathrm{~W}$ $\mathrm{m}^{-2}$. Overall, then, the two estimates are consistent, while the extrema in the POCM estimate are of larger magnitude than those in the coarser-resolution climatology.

Overall, the studies by Hsiung et al. [1989] and Bryan [1982] and this model analysis give a generally consistent picture of the seasonal heat transport cycle, though differing in details. The study of Carissimo et al. [1985] stands out as significantly different from the other estimates in both magnitude and overall structure.

\subsection{Seasonal Heat Balance}

In this section the fate of the transported energy is considered by examining the seasonal heat budget. The overall heat balance for a zonally integrated section can be considered to consist of four terms:

$$
\begin{aligned}
-\frac{\partial \text { heat storage }}{\partial t}= & \frac{\partial \text { advection }}{\partial y} \\
& + \text { surface flux }+ \text { diffusive flux. }
\end{aligned}
$$

The explicit diffusive flux in the model is small compared with the other terms in (10). A simple scaling argument shows that in this model, the diffusive flux of heat is of 

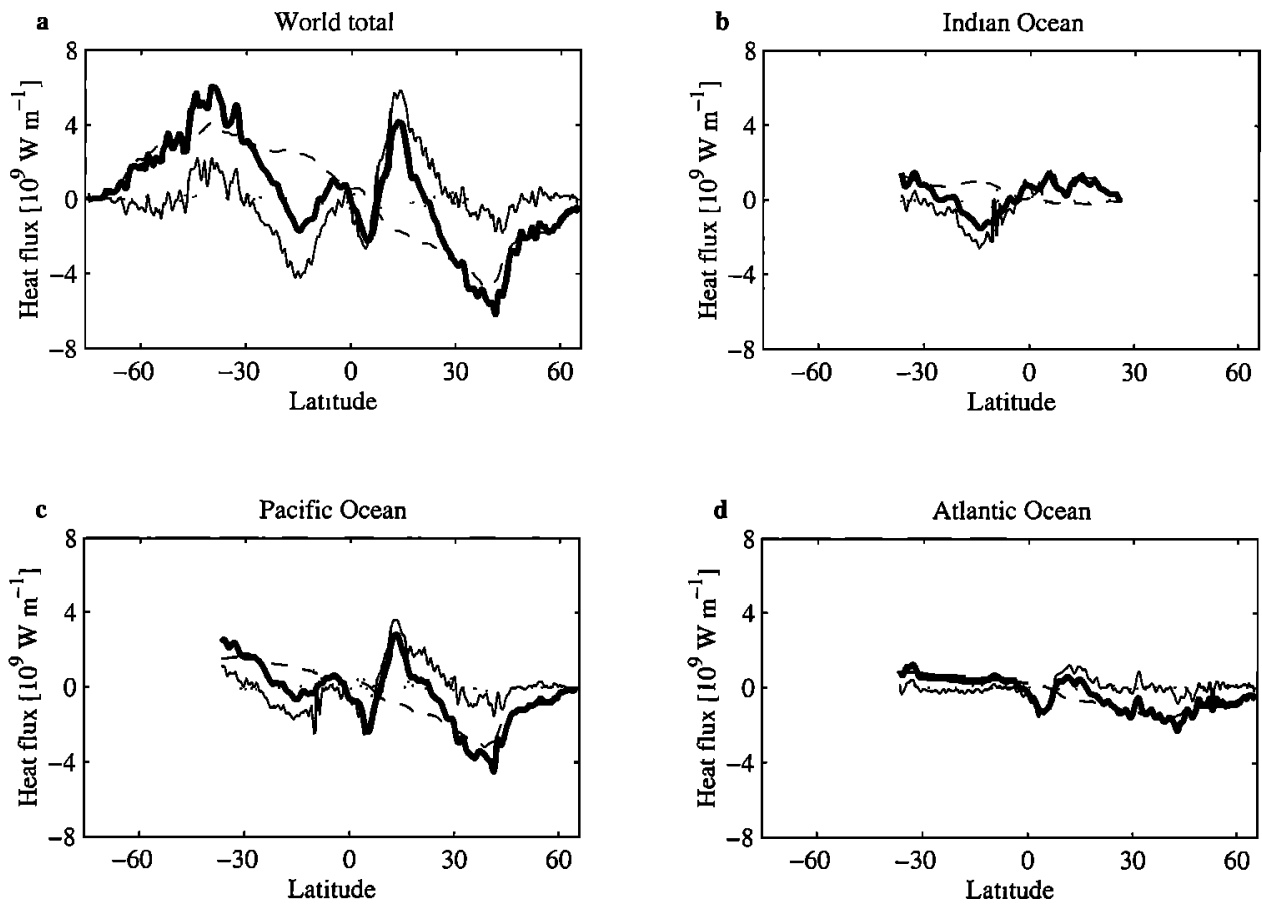

Figure 17. Seasonal heat balance for the zonally integrated (a) world ocean, (b) Indian Ocean, (c) Pacific Ocean, and (d) Atlantic Ocean. The bold curves are the seasonal change in heat storage, the thin solid curves are the divergence of the advective heat transport, the dashed curves are the surface flux component, and the dotted curves are the residual of the three terms. They are plotted such that the change in heat storage is equal to the sum of the divergence of the advective heat transport, the surface flux and the residual.

the order of $10^{7} \mathrm{~W} \mathrm{~m}^{-1}$ compared with other terms in the heat balance that are of the order of $10^{9} \mathrm{~W} \mathrm{~m}^{-1}$.

The seasonal component of the zonally integrated heat balance in shown in Figure 17. In the tropics out to $20^{\circ}$, the change in heat storage is balanced by the divergence of the advection, in agreement with results from the equatorial Atlantic of Merle [1980] and Böning and Herrmann [1994] and the northern and equatorial Indian Ocean [Lee and Marotzke, 1998]. The seasonal cycle is therefore different from the time mean, where the advective heat transport divergence is largely balanced by the surface flux. In this respect, most of the internal energy is moved around in the ocean, but little moves in and out, and its influence on climate is mollified. In the midlatitudes the approximate balance is between the surface flux and the change in heat storage, as predicted by theory [Gill and Niiler, 1973] and confirmed by observations [Hsiung et al., 1989]. In the middle latitudes the divergence of the heat transport does play a small but noticeable role in both hemispheres around $40^{\circ}$, consistent with the results of Hsiung et al. [1989] given the uncertainties in their calculation.

\subsection{Effects on Hydrographic Estimates of the Time Mean}

Many current estimates of the ocean's time-mean heat transport are based on one-time hydrographic sections. However, in light of the strong temporal variability discussed in this paper, we must ask how representative single snapshots of the ocean are of the time-mean circulation. This question can be addressed by decomposing the heat transport variability into contributions associated with the different dynamical overturning regimes discussed in section 3.2. The heat transports associated with the dynamical components are equivalent to the "barotropic," "Ekman," and "baroclinic" components of Hall and Bryden [1982]. The annual cycle associated with each of these components is shown in Figure 18. The Ekman mode dominates the total variability, with the same characteristics as were discussed in the previous section. The contribution from the barotropic circulation is small everywhere. Interestingly, there is a region of strong compensation between the baroclinic heat transport and Ekman heat transport in the area around $10^{\circ} \mathrm{N}$ in the Indian Ocean that is related to the strong monsoonal cycle there. This feature can also be seen in the analysis of the Indian Ocean by Lee and Marotzke [1998], but a satisfactory explanation is still outstanding.

The dynamical decomposition permits the separation of the Ekman heat transport from the rest of the timevarying transport. The total variance of the barotropic and baroclinic heat transport terms is now calculated to investigate how well one-time hydrographic sections can measure the time-mean heat transport. Figure 19 shows the root-mean-square of the non-Ekman (or barotropic plus baroclinic) heat transport (notice that the total variance is calculated here, not just the seasonal cycle). 

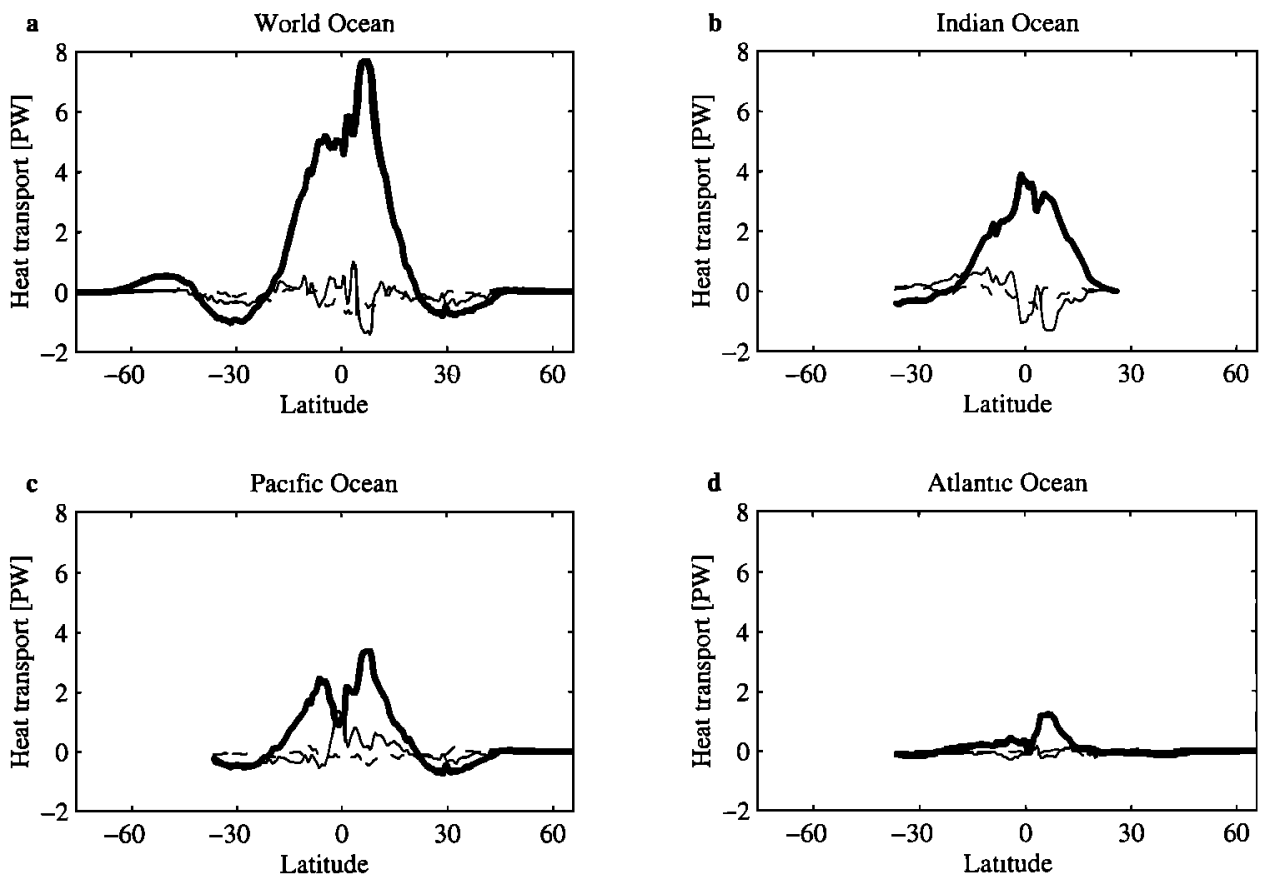

Figure 18. Annual cycle of heat transport associated with "barotropic" circulation (dashed curves), Ekman circulation (bold curves), and baroclinic shear flow (thin solid curves) for the world ocean, and the three ocean basins.

In the Atlantic Ocean, away from the equator, it is about 0.2 PW. The Pacific Ocean's midlatitude variations are large, around 0.3-0.4 PW, as are those in the southern Indian Ocean. This suggests that the heat transport estimates made from hydrography using the method of Hall and Bryden [1982] are good to within 0.2-0.4 PW.

So far we have discussed large spatial-scale variability and its effect on the heat transport. However, there are contributions to the heat transport that are made by

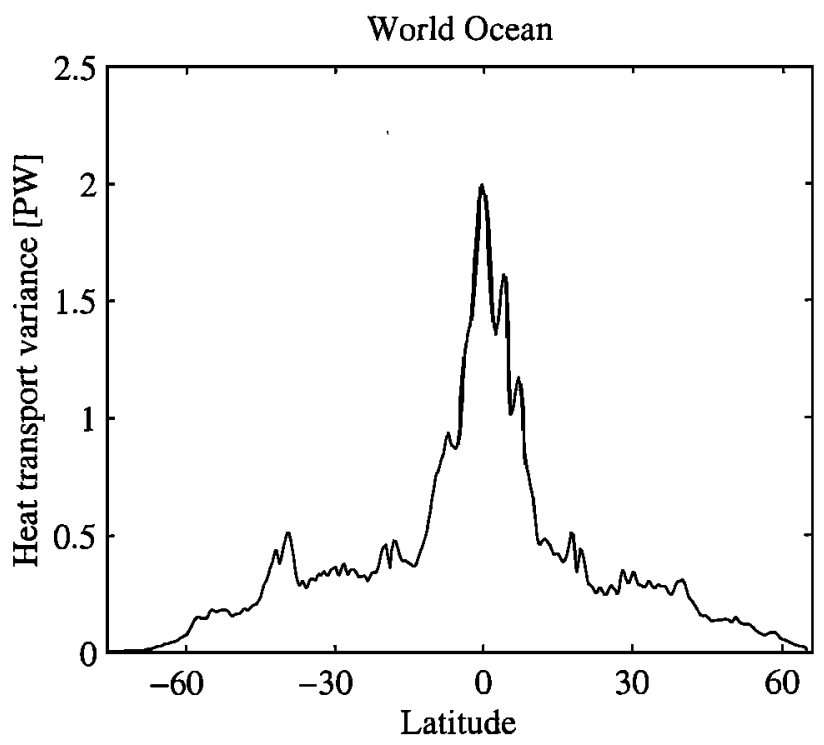

Figure 19. Root-mean-square variability of heat transport due to non-Ekman fluctuations for the world ocean. The square root of the variance is in units of petawatts. shorter-scale waves and vortices, which are hereinafter referred to as mesoscale eddy variability. The spacing between hydrographic stations is generally around 150 $200 \mathrm{~km}$ for the International Geophysical Year sections. The mesoscale eddy field is well resolved neither in space nor in time by such sampling. The WOCE program was designed to have higher-resolution sampling $(50-75 \mathrm{~km})$ so that the mesoscale eddies would not be aliased in space, but they are still aliased in time. The POCM does not fully resolve the mesoscale eddy field, as its resolution is coarser than the first-baroclinic Rossby radius, and as a result the model's mesoscale variability is about a factor 2-4 too weak [Stammer et al., 1996]. It is not clear how this affects the heat transport by mesoscale eddies.

The contribution to the heat transport by the mesoscale eddy field can be estimated by decomposing further the correlations in the deviations from the zonal mean velocity and zonal mean temperature. Hall and Bryden [1982] decomposed the baroclinic heat transport associated with the shear flow into the transport by the zonal mean of the shear flow and deviations from it. Let $v_{s h}$ be the baroclinic velocity at each point and be composed of the zonal average $\left[v_{s h}\right]$, and let deviations from that be $v_{s h}^{*}$.

$$
\begin{aligned}
\iint v_{s h} \theta d x d z= & \iint\left[v_{s h}\right][\theta] d x d z \\
& +\iint v_{s h}^{*} \theta^{*} d x d z,
\end{aligned}
$$




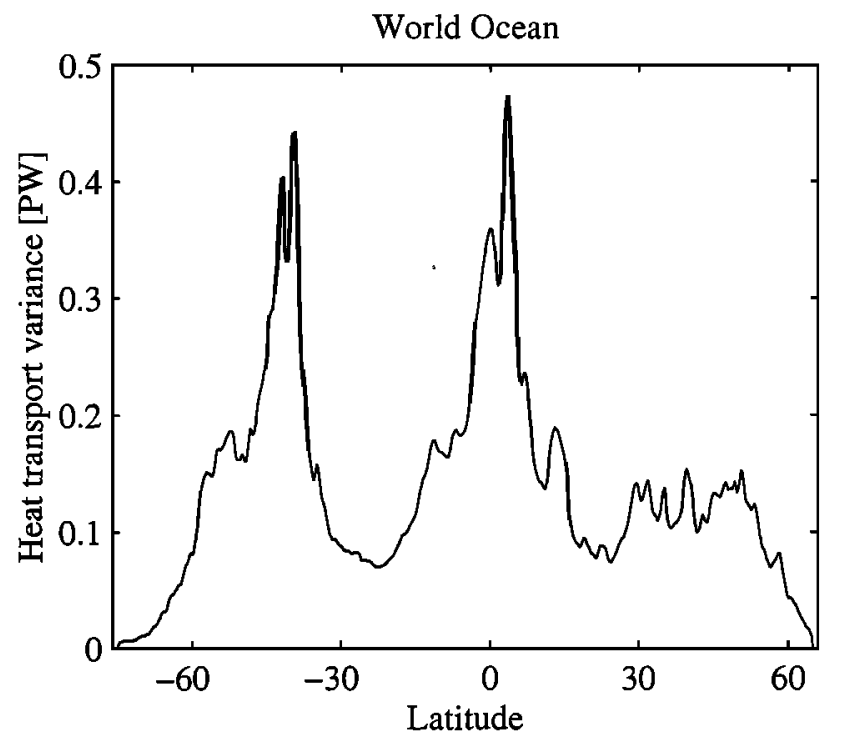

Figure 20. Root-mean-square variability of heat transport due to temporal changes in internal structure for the world ocean. The square root of the variance is in units of petawatts.

because the zonal integrals of $v_{s h}^{*}$ and $\theta^{*}$ are zero. The second term on the right-hand side of (11) is equivalent to what Hall and Bryden [1982] termed the "eddy contribution" to the heat transport. It is the smallness of the temporal variations in the eddy contribution to the heat transport that is essential to our ability to estimate the annual-mean ocean heat transport from compilations of one-time hydrographic sections. If the temporal variability of the heat transport due to the zonal structure of the section is large, then hydrographic surveys would be heavily aliased by the variability and hence be of limited usefulness. This is not the case, however, as is shown in Figure 20. The root-mean-square of the temporal fluctuations is small, of the order of $0.1 \mathrm{PW}$ over the midlatitude oceans. Its magnitude does increase in the tropics to $0.4 \mathrm{PW}$ for the world ocean. It is also about $0.4 \mathrm{PW}$ in the Antarctic Circumpolar Current, centered around $40^{\circ} \mathrm{S}$.

At $25^{\circ} \mathrm{N}$ in the Atlantic Ocean, Hall and Bryden [1982] found that the eddy contribution to the heat transport was very small, $0.016 \mathrm{PW}$, compared with the total of 1.2 PW and that most of the baroclinic heat transport was carried by the large-scale shear. However, the value of the eddy contribution was not a stable quantity, and they estimated that the term could be up to 15 times larger, or about $0.24 \mathrm{PW}$, which was $25 \%$ of the total heat transport. A more recent estimate by Baringer and Molinari [1999] finds a similar uncertainty of 0.26 PW for the same section. Here this term has been considered in a different manner. Its temporal variability has been computed to estimate how reliable one-time hydrographic sections are. At $25^{\circ} \mathrm{N}$ in the Atlantic, it has a root-meansquare variability of $0.05 \mathrm{PW}$, indicating that it is a very minor contributor to the time dependence of the heat transport. Away from the equator and Antarctic Cir- cumpolar Current, the mesoscale eddy field appears to have little impact on the time dependence of the ocean heat transport. Further, it suggests that hydrographic sections do an adequate job of sampling the heat transport due to the baroclinic shear. It is important to bear in mind, however, that the model is not adequately resolving the mesoscale eddy field, and therefore this result should be confirmed with a higher-resolution model.

\section{DISCUSSION AND CONCLUSIONS}

The role of variable wind stress in forcing ocean heat transport fluctuations has been discussed, and its dynamics have been explained. We have presented a cohesive dynamical model for the seasonal Ekman overturning circulation that was put forward by combining and extending the work of Schopf [1980], Willebrand et al. [1980], and Bryan [1982]. The seasonal cycle of the meridional overturning stream function is governed by a relatively simple set of dynamics compared with the time-mean meridional overturning. In particular, there is a near-complete compensation between the zonal integral of the Ekman mass transport and the depthindependent return flow. These dynamics appear to be very robust in OGCMs and are consistent with the recent results of Böning et al. [2001]. As part of the Dynamics of North Atlantic Models (DYNAMO) study, they found that three OGCMs that used different vertical coordinates (geopotential, isopycnic, and sigma coordinates), had significant differences in their mean states but were very similar in seasonal variability.

The salient dynamics can be summarized in the following argument: An oscillation in the zonal integral over the basin width of the zonal wind stress drives a corresponding change in the integrated meridional Ekman mass transport across that section. The change in the mass transport across the zonal section creates a pressure imbalance that through geostrophy and a series of gravity waves drives a depth-independent (barotropic) flow back across the section, balancing the initial change in the Ekman transport. Hence there is little net flow across the section. The response is essentially a shallow Ekman layer due to the wind stress, together with a compensating flow governed by barotropic dynamics. The adjustment to the change in the wind is fast, as the Ekman layer adjusts in an inertial period and the barotropic transport is set up by external gravity waves that can traverse the basin in under a day.

Within $25^{\circ}$ of the equator the observed seasonal cycle of the zonally integrated zonal wind is antisymmetric about the equator. The model of the thermally driven tropical atmospheric circulation (Hadley cell) of Gill [1980] explains this phenomenon well. The antisymmetry of the zonal wind drives an Ekman flow that is unidirectional and together with continuity and direct pressure forcing drives the flow across the equator. 
While this result was anticipated by the model of Gill [1980], we are unaware of previous discussions in the published literature, especially in the context of its impact on the ocean's meridional heat transport.

The seasonal cycle of meridional heat transport can be well described by a simple equation relating the zonal integral of the wind stress to the Ekman layer temperature and the section-averaged potential temperature. This equation is similar to the one used by Kraus and Levitus [1986], but we show that it only applies to the time-varying component of the Ekman heat transport, not the total (time-mean plus time-varying), as was previously assumed. The arguments presented give a new, sound dynamical foundation for understanding and estimation of the time-varying Ekman heat transport. The seasonal heat transport across the equator is directed from the summer hemisphere into the winter hemisphere, reinforcing the atmospheric energy transport by the Hadley circulation. In the traditional time-mean picture the ocean and atmosphere transport heat from the tropics toward the poles, tempering the equator-to-pole temperature difference. With this work it is now understood how the ocean on the seasonal timescale, in conjunction with the atmosphere, transports energy from the summer hemisphere to the winter hemisphere, moderating the seasonal cycle of ocean and atmospheric temperatures that would otherwise occur. This directly wind driven variability would also occur for any of the other ocean tracers, such as salt, nutrients, carbon dioxide $\left(\mathrm{CO}_{2}\right)$, or chlorofluorocarbons (CFCs), whose average Ekman layer concentration is different from the section average.

In the POCM, near the equator, the global ocean's seasonal heat transport has a peak-to-peak amplitude that ranges between 4.5 and $6 \mathrm{PW}$, slightly larger than the seasonal cycle of energy transport of the atmosphere. The seasonal cycle of the ocean's heat transport is larger than the amplitude of the time-mean ocean heat transport, particularly in the tropics. At $7^{\circ} \mathrm{N}$ the Atlantic and Pacific Oceans have their maximum amplitudes in the seasonal cycles of 1 and $3 \mathrm{PW}$, respectively. The Indian Ocean has its maximum peak-to-peak seasonal cycle of $2.6 \mathrm{PW}$ at $5^{\circ} \mathrm{S}$. At about $20^{\circ}$ from the equator, the seasonal cycle of the Ekman heat transport reverses sign, leading to a maximum convergence (divergence) of heat in the latitudes around $15^{\circ}$ in the winter (summer) hemisphere. In the tropics the advected energy produces the seasonal cycle in heat storage that is out of phase with the surface heat gain. In the midlatitudes the surface heat flux is largely in balance with storage, in agreement with the theory by Gill and Niller [1973]; however, in the Pacific Ocean the divergence of Ekman heat transport plays a small but noticeable role. At high latitudes the seasonal heating and cooling of the Ekman layer drives the time dependence of the heat transport there. The model's seasonal heat transport cycle is consistent with observational estimates [Hsiung et al., 1989].

Despite the Ekman transport's strong impact on the time-dependent heat transport, the largely depth indepen- dent character of its associated meridional overturning stream function means that the strong heat transport variability does not affect estimates of the time-mean heat transport made by one-time hydrographic surveys, provided that the Ekman layer contribution is estimated from the time-mean wind stress. The dynamical arguments presented here do not support the assumptions made by Bryden et al. [1991] that the ocean's response to the seasonal wind cycle is confined to the upper $700 \mathrm{~m}$. These results extend the study of Böning and Herrmann [1994], which were limited to the North Atlantic, to all the ocean basins. Away from the tropics the heat transport variability associated with the barotropic gyre and baroclinic circulations is much weaker than the Ekman variability and can amount to a $0.2-0.4 \mathrm{PW}$ variance in the heat transport measured by a one-time hydrographic survey. Hence estimates of the time-mean heat transport made from onetime hydrographic surveys using the method of Hall and Bryden [1982] are fundamentally sound.

This review has focused on the Ekman heat transport and its dynamics since they dominate the global picture. Locally, however, other dynamics may be important. Indeed, at $24^{\circ} \mathrm{N}$ in the Atlantic Ocean, Baringer and Molinari [1999] using repeat hydrography found an annual cycle in the baroclinic heat transport of about $0.5 \mathrm{PW}$ (peak to peak). This latitude happens to be near the node of the seasonal cycle of wind stress and as a result experiences a very small annual cycle in Ekman heat transport. Therefore at $24^{\circ} \mathrm{N}$ the largest contribution to the annual cycle comes from changes in the baroclinic structure. One of the goals of future observations and modeling efforts should be to understand these baroclinic heat transport variations, as well as longer timescale variability.

ACKNOWLEDGMENTS. Funding for this research came from the Department of Defense under a National Defense Science and Engineering Graduate Fellowship (S.R.J.), from the National Science Foundation, the American Automobile Manufacturers Association, and the Tokyo Electric Power Company through the TEPCO/MIT Environmental Research Program. The computational resources for this work were provided by the National Center for Atmospheric Research, which is supported by the National Science Foundation. Special thanks are due Robin Tokmakian and Bert Semtner, from the Naval Postgraduate School, who generously provided their numerical model output. We thank the anonymous reviewers, whose comments led to considerable improvement of the manuscript. This is a contribution to the World Ocean Circulation Experiment.

Thomas Torgersen and Tommy Dickey were the Editors responsible for this paper. They thank the anonymous technical and cross-disciplinary reviewers.

\section{REFERENCES}

Adamec, D., M. M. Rienecker, and J. M. Vukovich, The time-varying characteristics of the meridional Ekman heat 
transport for the world ocean, J. Phys. Oceanogr., 23, 27042716, 1993.

Anderson, D. L. T., K. Bryan, A. E. Gill, and R. C. Pacanowski, The transient response of the North Atlantic: Some model studies, J. Geophys. Res., 84, 4795-4815, 1979.

Baringer, M. O., and R. Molinari, Atlantic Ocean baroclinic heat flux at $24^{\circ}$ to $26^{\circ} \mathrm{N}$, Geophys. Res. Lett., 26, 353-356, 1999.

Barnier, B., L. Siefridt, and P. Marchesiello, Thermal forcing for a global ocean circulation model using a 3-year climatology of ECMWF analyses, J. Mar. Syst., 6, 363-380, 1995.

Böning, C. W., and P. Herrmann, Annual cycle of poleward heat transport in the ocean: Results from high-resolution modeling of the North and equatorial Atlantic, $J$. Phys. Oceanogr., 24, 91-107, 1994.

Böning, C. W., C. Dieterich, B. Barnier, and Y. Jia, Seasonal cycle of meridional heat transport in the subtropical North Atlantic: A model intercomparison in relation to observations near $25^{\circ} \mathrm{N}$, Prog. Oceanogr., in press, 2001.

Brink, K. H., Evidence for wind-driven current fluctuations in the western North Atlantic, J. Geophys. Res., 94, 2029-2044, 1989.

Bryan, K., Measurements of meridional heat transport by ocean currents, J. Geophys. Res., 67, 3403-3414, 1962.

Bryan, K., Seasonal variation in meridional overturning and poleward heat transport in the Atlantic and Pacific Oceans: A model study, J. Mar. Res., 40, suppl., 39-53, 1982.

Bryan, K., and L. J. Lewis, A water mass model of the world ocean, J. Geophys. Res., 84, 2503-2517, 1979.

Bryden, H. L., D. H. Roemmich, and J. A. Church, Ocean heat transport across $24^{\circ} \mathrm{N}$ in the Pacific, Deep Sea Res., Ser. I, 38 , 297-324, 1991.

Carissimo, B. C., A. H. Oort, and T. H. Vonder Haar, Estimating the meridional energy transports in the atmosphere and ocean, J. Phys. Oceanogr., 15, 82-91, 1985.

Chao, Y., and L.-L. Fu, A comparison between the TOPEX/ Poseidon data and a global ocean general circulation model during 1992-1993, J. Geophys. Res., 100, 24,965-24,976, 1995.

Chave, A. D., D. S. Luther, and J. H. Filloux, The Barotropic Electromagnetic and Pressure Experiment, 1, Barotropic current response to atmospheric forcing, J. Geophys. Res., 97, 9565-9593, 1992.

Dukowicz, J., and R. D. Smith, Implicit free-surface method for the Bryan-Cox-Semtner ocean model, J. Geophys. Res., 99, 7991-8014, 1994.

England, M. H., V. Garçon, and J.-F. Minster, Cholorfluorocarbon uptake in a world ocean model, 1, Sensitivity to the surface gas forcing, J. Geophys. Res., 99, 25,215-25,233, 1994.

Fu, L.-L., and R. A. Davidson, A note on the barotropic response of sea level to time-dependent wind forcing, $J$. Geophys. Res., 100, 24,955-24,963, 1995.

Fu, L.-L., and R. D. Smith, Global ocean circulation from satellite altimetry and high-resolution computer simulation, Bull. Am. Meteorol. Soc., 77, 2625-2636, 1996.

Fukumori, I., R. Raghunath, and L.-L. Fu, Nature of global large-scale sea level variability in relation to atmospheric forcing: A modeling study, J. Geophys. Res., 103, 5493-5512, 1998.

Ganachaud, A., Large scale oceanic circulation and fluxes of freshwater, heat, nutrients and oxygen, Ph.D. thesis, Mass. Inst. of Technol./Woods Hole Oceanogr. Inst. Joint Program, Cambridge, Mass., 1999.

Ganachaud, A., and C. Wunsch, Improved estimates of global ocean circulation, heat transport and mixing from hydrographic data, Nature, 408, 453-457, 2000.

Ganachaud, A., C. Wunsch, J. Marotzke, and J. Toole, Meridional overturning and large-scale circulation of the Indian Ocean, J. Geophys. Res., 105, 26,117-26,134, 2000.

Garternicht, U., and F. Schott, Heat fluxes of the Indian Ocean from a global eddy-resolving model, J. Geophys. Res., 102, 21,147-21,159, 1997.

Ghirardelli, J. E., M. M. Rienecker, and D. Adamec, Meridi- onal Ekman heat transport: Estimates from satellite data, $J$. Phys. Oceanogr., 25, 2741-2755, 1995.

Gill, A. E., Some simple solutions for heat-induced tropical circulation, Q. J. R. Meteorol. Soc., 106, 447-462, 1980.

Gill, A. E., and P. P. Niiler, The theory of the seasonal variability in the ocean, Deep Sea Res., 20, 141-178, 1973.

Gordon, A. L., and J. L. McClean, Thermohaline stratification of the Indonesian seas: Model and observations, J. Phys. Oceanogr., 29, 198-216, 1999.

Hadley, G., Concerning the cause of the general trade winds, Philos. Trans. R. Soc. London, Ser. A, 39, 58-62, 1735.

Hall, M. M., and H. L. Bryden, Direct estimates and mechanisms of ocean heat transport, Deep Sea Res., 29, 339-359, 1982.

Halley, E., An historical account of the trade winds, and monsoons, observable in the seas between and near the tropics, with an attempt to assign the physical cause of the said winds, Philos. Trans. R. Soc. London, Ser. A, 16, 153-168, 1686.

Haney, R. L., Surface thermal boundary condition for ocean climate models, J. Phys. Oceanogr., 1, 241-248, 1971.

Hastenrath, S., On meridional heat transports in the world ocean, J. Phys. Oceanogr., 12, 922-927, 1982.

Hellerman, S., An updated estimate of the wind stress on the world ocean, Mon. Weather Rev., 95, 607-626, 1967. (Correction, Mon. Weather Rev., 96, 63-74, 1968.)

Hellerman, S., and M. Rosenstein, Normal monthly wind stress over the world ocean with error estimates, J. Phys. Oceanogr., 13, 1093-1104, 1983.

Hsiung, J., R. E. Newell, and T. Houghtby, The annual cycle of oceanic heat storage and oceanic meridional heat transport, Q. J. R. Meteorol. Soc., 115, 1-28, 1989.

Jayne, S. R., and R. Tokmakian, Forcing and sampling of ocean general circulation models: Impact of high-frequency motions, J. Phys. Oceanogr., 27, 1173-1179, 1997.

Keith, D. W., Meridional energy transport, uncertainty in zonal means, Tellus, Ser. A, 47, 30-44, 1995.

Klinger, B. A., and J. Marotzke, Meridional heat transport by the subtropical cell, J. Phys. Oceanogr., 30, 696-705, 2000.

Kobayashi, T., and N. Imasato, Seasonal variability of heat transport derived from hydrographic and wind stress data, $J$. Geophys. Res., 103, 24,663-24,674, 1998.

Koblinsky, C. J., and P. P. Niiler, The relationship between deep ocean currents and winds east of Barbados, J. Phys. Oceanogr., 12, 144-153, 1982.

Koblinsky, C. J., P. P. Niiler, and W. J. Schmitz, Observations of wind-forced deep ocean currents in the North Pacific, $J$. Geophys. Res., 94, 10,773-10,790, 1989.

Kraus, E. B., and S. Levitus, Annual heat flux variations across the tropic circles, J. Phys. Oceanogr., 16, 1479-1486, 1986.

Lamb, P. J., and A. F. Bunker, The annual march of the heat budget of the North and tropical Atlantic Oceans, J. Phys. Oceanogr., 12, 1388-1410, 1982.

Large, W. G., J. C. McWilliams, and S. C. Doney, Oceanic vertical mixing: A review and a model with nonlocal boundary layer parameterization, Rev. Geophys., 32, 363-403, 1994.

Lau, K. M. W., Experiment with a simple ocean-atmosphere climate model: The role of the ocean in the global climate, J. Atmos. Sci., 35, 1144-1163, 1978.

Lee, T., and J. Marotzke, Seasonal cycles of meridional overturning and heat transport of the Indian Ocean, J. Phys. Oceanogr., 28, 923-943, 1998.

Levitus, S., Climatological atlas of the world ocean, NOAA Prof. Pap. 13, 173 pp., U.S. Govt. Print. Office, Washington, D. C., 1982.

Levitus, S., Meridional Ekman heat fluxes for the world ocean and individual ocean basins, J. Phys. Oceanogr., 17, 14841492, 1987.

Levitus, S., and T. P. Boyer, World Ocean Atlas 1994, vol. 4, Temperature, NOAA Atlas NESDIS 4, 129 pp., Natl. Oceanic and Atmos. Admin., Silver Spring, Md., 1994. 
Levitus, S., and A. H. Oort, Global analysis of oceanographic data, Bull. Am. Meteorol. Soc., 58, 1270-1284, 1977.

Levitus, S., R. Burgett, and T. Boyer, World Ocean Atlas 1994, vol. 3, Salinity, NOAA Atlas NESDIS 3, 111 pp., Natl. Oceanic and Atmos. Admin., Silver Spring, Md., 1994.

Luther, D. S., A. D. Chave, J. H. Filloux, and P. F. Spain, Evidence for local and nonlocal barotropic responses to atmospheric forcing during the Barometric Electromagnetic and Pressure Experiment (BEMPEX), Geophys. Res. Lett., 17, 949-952, 1990.

Macdonald, A. M., and C. Wunsch, An estimate of global ocean circulation and heat fluxes, Nature, 382, 436-439, 1996.

Maltrud, M. E., R. D. Smith, A. J. Semtner, and R. C. Malone, Global eddy resolving ocean simulations driven by 19851995 atmospheric winds, $J$. Geophys. Res., 103, 30,82530,853, 1998.

McClean, J. L., A. J. Semtner, and V. Zlotnicki, Comparisons of mesoscale variability in the Semtner-Chervin $1 / 4^{\circ}$ model, the Los Alamos Parallel Ocean Program $1 / 6^{\circ}$ model, and TOPEX/Poseidon data, J. Geophys. Res., 102, 25,203-25,226, 1997.

McCreary, J. P., P. K. Kundu, and R. L. Molinari, A numerical investigation of dynamics, thermodynamics and mixed-layer processes in the Indian Ocean, Prog. Oceanogr., 31, 181244, 1993.

Meehl, G. A., W. M. Washington, and A. J. Semtner, Experiments with a global ocean model driven by observed atmospheric forcing, J. Phys. Oceanogr., 12, 301-312, 1982.

Merle, J., Seasonal heat budget in the equatorial Atlantic Ocean, J. Phys. Oceanogr., 10, 464-469, 1980.

Molinari, R. L., E. Johns, and J. F. Festa, The annual cycle of meridional heat flux in the Atlantic Ocean at $26.5^{\circ} \mathrm{N}, J$. Phys. Oceanogr., 20, 476-482, 1990.

Nakano, H., R. Furue, and N. Suginohara, Effect of seasonal forcing on global circulation in a world ocean general circulation model, Clim. Dyn., 15, 491-502, 1999.

Niiler, P. P., and C. J. Koblinsky, A local time-dependent Sverdrup balance in the eastern North Pacific Ocean, Science, 229, 754-756, 1985.

Niiler, P. P., J. Filloux, W. T. Liu, R. M. Samelson, J. D. Paduan, and C. A. Paulson, Wind-forced variability of the deep eastern North Pacific: Observations of seafloor pressure and abyssal currents, J. Geophys. Res., 98, 22,58922,602, 1993.

Oort, A. H., and T. H. Vonder Haar, On the observed annual cycle in the ocean-atmosphere heat balance over the Northern Hemisphere, J. Phys. Oceanogr., 6, 781-800, 1976.

Peixoto, J. P., and A. H. Oort, Physics of Climate, Am. Inst. of Phys., College Park, Md., 1992.

Philander, S. G. H., Forced oceanic waves, Rev. Geophys., 16, 15-46, 1978.

Philander, S. G. H., and R. C. Pacanowski, The mass and heat budget in a model of the tropical Atlantic Ocean, J. Geophys. Res., 91, 14,212-14,220, 1986.

Ponte, R. M., and R. D. Rosen, Oceanic angular momentum and torques in a general circulation model, J. Phys. Oceanogr., 24, 1966-1977, 1994.

Ponte, R. M., D. Stammer, and J. Marshall, Oceanic signals in observed motions of the Earth's pole of rotation, Nature, 391, 476-479, 1998.

Roemmich, D., and C. Wunsch, Two transatlantic sections: Meridional circulation and heat flux in the subtropical North Atlantic Ocean, Deep Sea Res., Ser. I, 32, 619-664, 1985.

Rosen, R. D., D. A. Salstein, and T. M. Wood, Discrepancies in the Earth-atmosphere angular momentum budget, $J$. Geophys. Res., 95, 265-279, 1990.

Samelson, R. M., Evidence for wind-driven current fluctua- tions in the eastern North Atlantic, J. Geophys. Res., 95, 11,359-11,368, 1990.

Sato, O. T., and T. Rossby, Seasonal and low-frequency variability of the meridional heat flux at $36^{\circ} \mathrm{N}$ in the North Atlantic, J. Phys. Oceanogr., 30, 606-621, 2000.

Schopf, P. S., The role of Ekman flow and planetary waves in the oceanic cross-equatorial heat transport, J. Phys. Oceanogr., 10, 330-341, 1980.

Semtner, A. J., and R. M. Chervin, A simulation of the global ocean circulation with resolved eddies, J. Geophys. Res., 93, 15,502-15,522, 15,767-15,775, 1988.

Semtner, A. J., and R. M. Chervin, Ocean general circulation from a global eddy-resolving model, J. Geophys. Res., 97, 5493-5550, 1992.

Stammer, D., R. Tokmakian, A. J. Semtner, and C. Wunsch, How well does a $1 / 4^{\circ}$ global circulation model simulate large-scale oceanic observations?, J. Geophys. Res., 101, 25,779-25,811, 1996.

Stammer, D., C. Wunsch, and R. Ponte, Dealiasing of global high-frequency barotropic motions in altimeter observations, Geophys. Res. Lett., 27, 1175-1178, 2000.

Tierney, C., J. Wahr, F. Bryan, and V. Zlotnicki, Short-period oceanic circulation: Implications for satellite altimetry, Geophys. Res. Lett., 27, 1255-1258, 2000.

Trenberth, K. E., and A. Solomon, The global heat balance: Heat transports in the atmosphere and ocean, Clim. Dyn., 10, 107-134, 1994.

Trenberth, K. E., J. M. Caron, and D. P. Stephaniak, Estimates of meridional atmosphere and ocean heat transports, J. Clim., in press, 2001.

Veronis, G., and H. Stommel, The action of variable wind stresses on a stratified ocean, J. Mar. Res., 15, 43-75, 1956.

Vinnichenko, N. K., The kinetic energy spectrum in the free atmosphere-One second to 5 years, Tellus, 22, 158-166, 1970.

Vonder Haar, T. H., and A. H. Oort, New estimate of annual poleward energy transport by Northern Hemisphere oceans, J. Phys. Oceanogr., 3, 169-172, 1973.

Wacongne, S., and R. Pacanowski, Seasonal heat transport in a primitive equation model of the tropical Indian Ocean, $J$. Phys. Oceanogr., 26, 2666-2699, 1996.

Warren, B. A., Approximating the energy transport across oceanic sections, J. Geophys. Res., 104, 7915-7919, 1999.

Wilkin, J. L., J. V. Mansbridge, and J. S. Godfrey, Pacific Ocean heat transport at $24^{\circ} \mathrm{N}$ in a high-resolution global model, J. Phys. Oceanogr., 25, 2204-2214, 1995.

Willebrand, J., Temporal and spatial scales of the wind field over the North Pacific and North Atlantic, J. Phys. Oceanogr., 8, 1080-1094, 1978.

Willebrand, J., S. G. H. Philander, and R. C. Pacanowski, The oceanic response to large-scale atmospheric disturbances, $J$. Phys. Oceanogr., 10, 411-429, 1980.

$\mathrm{Yu}, \mathrm{L}$., and P. Malanotte-Rizzoli, Inverse modeling of seasonal variations in the North Atlantic Ocean, J. Phys. Oceanogr. 28, 902-922, 1998.

Zhang, Q., and J. Marotzke, The importance of open-boundary estimation for an Indian Ocean GCM-data synthesis, $J$. Mar. Res., 57, 305-334, 1999.

S. R. Jayne, Climate and Global Dynamics Division, National Center for Atmospheric Research, P.O. Box 3000, 1850 Table Mesa Drive, Boulder, CO 80307-3000, USA. (surje@alum. mit.edu)

J. Marotzke, School of Ocean and Earth Science, University of Southampton, Southampton Oceanography Centre, European Way, Southampton S014 3ZH, England UK. (Jochem. Marotzke@soc.soton.ac.uk) 